\title{
The Impact of Default Dependency and \\ Collateralization on Asset Pricing and Credit Risk Modeling
}

\author{
Tim Xiao ${ }^{1}$
}

\begin{abstract}
This article presents a comprehensive framework for valuing financial instruments subject to credit risk. In particular, we focus on the impact of default dependence on asset pricing, as correlated default risk is one of the most pervasive threats in financial markets. We analyze how swap rates are affected by bilateral counterparty credit risk, and how CDS spreads depend on the trilateral credit risk of the buyer, seller, and reference entity in a contract. Moreover, we study the effect of collateralization on valuation, since the majority of OTC derivatives are collateralized. The model shows that a fully collateralized swap is risk-free, whereas a fully collateralized CDS is not equivalent to a risk-free one.
\end{abstract}

Key Words: asset pricing; credit risk modeling; unilateral, bilateral, multilateral credit risk; collateralization; comvariance; comrelation; correlation

\footnotetext{
${ }^{1}$ Risk Analytics, Capital Markets Risk Management, CIBC, 161 Bay Street, Toronto, ON M5J 2S8, Canada; email: tim_yxiao@yahoo.com or tim.xiao@finpricing.com Url: https://finpricing.com/
} 


\section{Introduction}

A broad range of financial instruments bear credit risk. Credit risk may be unilateral, bilateral, or multilateral. Some instruments such as, loans, bonds, etc, by nature contain only unilateral credit risk because only the default risk of one party appears to be relevant, whereas some other instruments, such as, over the counter (OTC) derivatives, securities financing transactions (SFT), and credit derivatives, bear bilateral or multilateral credit risk because two or more parties are susceptible to default risk. This paper mainly discusses bilateral and multilateral credit risk modeling, with a particular focus on default dependency, as correlated credit risk is one of the greatest threats to global financial markets.

There are two primary types of models that attempt to describe default processes in the literature: structural models and reduced-form (or intensity) models. Many practitioners in the credit trading arena have tended to gravitate toward the reduced-from models given their mathematical tractability. They can be made consistent with the risk-neutral probabilities of default backed out from corporate bond prices or credit default swap (CDS) spreads/premia.

Central to the reduced-form models is the assumption that multiple defaults are independent conditional on the state of the economy. In reality, however, the default of one party might affect the default probabilities of other parties. Collin-Dufresne et al. (2003) and Zhang and Jorion (2007) find that a major credit event at one firm is associated with significant increases in the credit spreads of other firms. Giesecke (2004), Das et al. (2006), and Lando and Nielsen (2010) find that a defaulting firm can weaken the firms in its network of business links. These findings have important implications for the management of credit risk portfolios, where default relationships need to be explicitly modeled.

The main drawback of the conditionally independent assumption or the reduced-form models is that the range of default correlations that can be achieved is typically too low when compared with empirical default correlations (see Das et al. (2007)). The responses to correct this weakness can be generally classified into two categories: endogenous default relationship approaches and exogenous default relationship approaches. 
The endogenous approaches include the contagion (or infectious) models and frailty models. The frailty models (see Duffie et al. (2009), Koopman et al. (2011), etc) describe default clustering based on some unobservable explanatory variables. In variations of contagion or infectious type models (see Davis and Lo (2001), Jarrow and Yu (2001), etc.), the assumption of conditional independence is relaxed and default intensities are made to depend on default events of other entities. Contagion and frailty models fill an important gap but at the cost of analytic tractability. They can be especially difficult to implement for large portfolios.

The exogenous approaches (see Li (2000), Laurent and Gregory (2005), Hull and White (2004), Brigo et al. (2011), etc) attempt to link marginal default probability distributions to the joint default probability distribution through some external functions. Due to their simplicity in use, the exogenous approaches become very popular in practice.

Collateralization is one of the most important and widespread credit risk mitigation techniques used in derivatives transactions. According the ISDA (2012), 71\% of all OTC derivatives transactions are subject to collateral agreements. The use of collateral in the financial markets has increased sharply over the past decade, yet the research on collateralized valuation is relatively sparse. Previous studies seem to turn away from direct and detailed modeling of collateralization (see Fuijii and Takahahsi (2012)). For example, Johannes and Sundaresan (2007), and Fuijii and Takahahsi (2012) characterize collateralization via a cost-of-collateral instantaneous rate (or stochastic dividend or convenience yield). Piterbarg (2010) regards collateral as a regular asset in a portfolio and uses the replication approach to price collateralized contracts.

This paper presents a new framework for valuing defaultable financial instruments with or without collateral arrangements. The framework characterizes default dependencies exogenously, and models collateral processes directly based on the fundamental principals of collateral agreements. Some well-known risky valuation models in the markets, e.g., the CDS model, the risky interest rate swap (IRS) model (Duffie and Huang (1996)), can be viewed as special cases of this framework, when the default dependencies are ignored. 
IRSs and CDSs are two of the largest segments of the OTC derivatives market, collectively accounting for around two-thirds of both the notional amount and market value of all outstanding derivatives. Given this framework, we are able to analyze the value of IRSs with bilateral credit risk and look at how swap rates are affected by correlated default risk. Our study shows that counterparty default correlations have a relatively small impact on swap rates. Furthermore, we find that the value of a fully collateralized IRS is equal to the risk-free value. This conclusion is consistent with the current market practice in which market participants commonly assume fully collateralized swaps are risk-free.

We also study the value of CDS contracts with trilateral credit risk and assess how spreads depend on the risk of the buyer, seller, and reference entity in a CDS contract. In general, a CDS contract is used to transfer the credit risk of a reference entity from one party to another. The risk circularity that transfers one type of risk (reference credit risk) into another (counterparty credit risk) within the CDS market is a concern for financial stability. Some people claim that the CDS market has increased financial contagion or even propose an outright ban on these instruments.

The standard CDS pricing model in the market assumes that there is no counterparty risk. Although this oversimplified model may be accepted in normal market conditions, its reliability in times of distress has recently been questioned. In fact, counterparty risk has become one of the most dangerous threats to the CDS market. For some time now it has been realized that, in order to value a CDS properly, counterparty effects have to be taken into account (see ECB (2009)).

We bring the concept of comvariance into the area of credit risk modeling to capture the statistical relationship among three or more random variables. Comvariance was first introduced to economics by Deardorff (1982), who used this measurement to correlate three factors in international trading. Furthermore, we define a new statistics, comrelation, as a scaled version of comvariance. Accounting for default correlations and comrelations becomes important in determining CDS premia, especially during the credit crisis. Our analysis shows that the effect of default dependencies on CDS premia from large to small is i) the default correlation between the protection seller and the reference entity, ii) the default comrelation, iii) the default correlation between the protection buyer and the 
reference entity, and iv) the default correlation between the protection buyer and the protection seller. In particular, we find that the default comvariance/comrelation has substantial effects on the asset pricing and risk management, which have never been documented.

There is a significant increase in the use of collateral for CDS after the recent financial crises. Many people believe that, if a CDS is fully collateralized, there is no risk of failure to pay. Collateral posting regimes are originally designed and utilized for bilateral risk products, e.g., IRS, but there are many reasons to be concerned about the success of collateral posting in offsetting the risk of CDS contracts. First, the value of CDS contracts tends to move very suddenly with big jumps, whereas the price movement of IRS contracts is far smoother and less volatile than CDS. Second, CDS spreads can widen very rapidly. Third, CDS contracts have many more risk factors than IRS contracts. In fact, our model shows that full collateralization cannot eliminate counterparty risk completely for a CDS.

This article also shows that the pricing process of a defaultable instrument normally has a backward recursive nature if the payoff can be positive or negative. Accordingly, we propose a backward induction approach for risky valuation. In contrast to the popular recursive integral solution (see Duffie and Huang (1996)), our backward induction method significantly simplifies the implementation. One can make use of the well-established algorithms, such as lattice/tree and regression-based Monte Carlo, to price a defaultable instrument.

The rest of this paper is organized as follows: Pricing bilateral defaultable instruments is elaborated on in Section 2; valuing multilateral defaultable instruments is discussed in Section 3; the conclusions are presented in Section 4. All proofs and some detailed derivations are contained in the appendices.

\section{Pricing Financial Instruments Subject to Bilateral Credit Risk}


We consider a filtered probability space $\left(\Omega, F,\left\{F_{t}\right\}_{t \geq 0}, P\right)$ satisfying the usual conditions, where $\Omega$ denotes a sample space, $F$ denotes a $\sigma$-algebra, $P$ denotes a probability measure, and $\left\{F_{t}\right\}_{t \geq 0}$ denotes a filtration.

In the reduced-form approach, the stopping (or default) time $\tau_{i}$ of firm $i$ is modeled as a Cox arrival process (also known as a doubly stochastic Poisson process) whose first jump occurs at default and is defined by,

$$
\tau_{i}=\inf \left\{t: \int_{0}^{t} h_{i}\left(s, Z_{s}\right) d s \geq H_{i}\right\}
$$

where $h_{i}(t)$ or $h_{i}\left(t, Z_{t}\right)$ denotes the stochastic hazard rate or arrival intensity dependent on an exogenous common state $Z_{t}$, and $H_{i}$ is a unit exponential random variable independent of $Z_{t}$.

Dependence between the default times is only introduced by the dependence of the intensity $h_{i}(t)$ on a common process $Z_{t}$. Consequently, conditional on the path of $Z_{t}$, defaults are independent, which is the reason why this setup is also often called the conditional independence setup.

It is well-known that the survival probability from time $t$ to $s$ in this framework is defined by

$$
p_{i}(t, s):=P_{i}\left(\tau>s \mid \tau>t, Z_{t}\right)=\exp \left(-\int_{t}^{s} h_{i}(u) d u\right)
$$

The default probability for the period $(t, s)$ in this framework is given by

$$
q_{i}(t, s):=P_{i}\left(\tau \leq s \mid \tau>t, Z_{t}\right)=1-p_{i}(t, s)=1-\exp \left(-\int_{t}^{s} h_{i}(u) d u\right)
$$

Three different recovery models exist in the literature. The default payoff is either i) a fraction of par (Madan and Unal (1998)), ii) a fraction of an equivalent default-free bond (Jarrow and Turnbull (1995)), or iii) a fraction of market value (Duffie and Singleton (1999)). The whole course of the recovery proceedings under the Bankruptcy and Insolvency act is a complex process that typically involves extensive negotiation and litigation. No model can fully capture all aspects of this process so, in practice, all models involve trade-offs between different perspectives and views. In general, the choice for a certain recovery assumption is based on the legal structure of an instrument to be priced. For example, the 
recovery of market value (RMV) assumption is well matched to the legal structure of an IRS contract where, upon default close-out, valuation will in many circumstances reflect the replacement cost of the transaction, whereas the best default recovery assumption for a CDS is that the claim made in the event of the reference default equals a fraction of the face value of the underlying bond.

There is ample evidence that corporate defaults are correlated. The default of a firm's counterparty might affect its own default probability. Thus, default correlation/dependence arises due to the counterparty relations.

Two counterparties are denoted as $A$ and $B$. The binomial default rule considers only two possible states: default or survival. Therefore, the default indicator $Y_{j}$ for party $j(j=A, B)$ follows a Bernoulli distribution, which takes value 1 with default probability $q_{j}$, and value 0 with survival probability $p_{j}$, i.e., $P\left\{Y_{j}=0\right\}=p_{j}$ and $P\left\{Y_{j}=1\right\}=q_{j}$. The marginal default distributions can be determined by the reduced-form models. The joint distributions of a multivariate Bernoulli variable can be easily obtained via the marginal distributions by introducing extra correlations.

Consider a pair of random variables $\left(Y_{A}, Y_{B}\right)$ that has a bivariate Bernoulli distribution. The joint probability representations are given by

$$
\begin{aligned}
& p_{00}:=P\left(Y_{A}=0, Y_{B}=0\right)=p_{A} p_{B}+\sigma_{A B} \\
& p_{01}:=P\left(Y_{A}=0, Y_{B}=1\right)=p_{A} q_{B}-\sigma_{A B} \\
& p_{10}:=P\left(Y_{A}=1, Y_{B}=0\right)=q_{A} p_{B}-\sigma_{A B} \\
& p_{11}:=P\left(Y_{A}=1, Y_{B}=1\right)=q_{A} q_{B}+\sigma_{A B}
\end{aligned}
$$

where $E\left(Y_{j}\right)=q_{j}, \sigma_{j}^{2}=p_{j} q_{j}$, and $\sigma_{A B}:=E\left[\left(Y_{A}-q_{A}\right)\left(Y_{B}-q_{B}\right)\right]=\rho_{A B} \sigma_{A} \sigma_{B}=\rho_{A B} \sqrt{q_{A} p_{A} q_{B} p_{B}}$ where $\rho_{A B}$ denotes the default correlation coefficient, and $\sigma_{A B}$ denotes the default covariance.

A critical ingredient of the pricing of a bilateral defaultable instrument is the default settlement rules. There are two rules in the market. The one-way payment rule was specified by the early International Swap Dealers Association (ISDA) master agreement. The non-defaulting party is not 
obligated to compensate the defaulting party if the remaining market value of the instrument is positive for the defaulting party. The two-way payment rule is based on current ISDA documentation. The nondefaulting party will pay the full market value of the instrument to the defaulting party if the contract has positive value to the defaulting party.

\subsection{Risky valuation without collateralization}

Consider a defaultable instrument that promises to pay a $X_{T}$ from party $B$ to party $A$ at maturity date $T$, and nothing before date $T$. The payoff $X_{T}$ may be positive or negative, i.e. the instrument may be either an asset or a liability to each party. All calculations are from the perspective of party $A$.

We divide the time period $(t, T)$ into $n$ very small time intervals $(\Delta t)$ and use the approximation $\exp (y) \approx 1+y$ provided that $y$ is very small. The survival and the default probabilities for the period $(t$, $t+\Delta t)$ are given by

$$
\begin{aligned}
& \hat{p}(t):=p(t, t+\Delta t)=\exp (-h(t) \Delta t) \approx 1-h(t) \Delta t \\
& \hat{q}(t):=q(t, t+\Delta t)=1-\exp (-h(t) \Delta t) \approx h(t) \Delta t
\end{aligned}
$$

Suppose that the value of the instrument at time $t+\Delta t$ is $V(t+\Delta t)$ that can be an asset or a liability. There are a total of four $\left(2^{2}=4\right)$ possible states shown in Table 1 .

The risky value of the instrument at time $t$ is the discounted expectation of all the payoffs and is given by

$$
\begin{aligned}
V(t)= & E\left\{\operatorname { e x p } ( - r ( t ) \Delta t ) \left[1_{V(t+\Delta t) \geq 0}\left\langle p_{00}(t)+\varphi_{B}(t) p_{01}(t)+\bar{\varphi}_{B}(t) p_{10}(t)+\varphi_{A B}(t) p_{11}(t)\right\rangle V(t+\Delta t) \mid \mathrm{F}_{\mathrm{t}}\right.\right. \\
& \left.\left.+1_{V(t+\Delta t)<0}\left\langle p_{00}(t)+\bar{\varphi}_{A}(t) p_{01}(t)+\varphi_{A}(t) p_{10}(t)+\varphi_{A B}(t) p_{11}(t)\right\rangle V(t+\Delta t) \mid \mathrm{F}_{\mathrm{t}}\right]\right\} \\
\approx & E\left\{\exp \left[-\left(r(t)+1_{V(t+\Delta t) \geq 0} l_{B}(t)+1_{V(t+\Delta t)<0} l_{A}(t)\right) \Delta t\right] V(t+\Delta t) \mid \mathrm{F}_{\mathrm{t}}\right\}=E\left\{\exp (-g(t) \Delta t) V(t+\Delta t) \mid \mathrm{F}_{\mathrm{t}}\right\}
\end{aligned}
$$

where

$$
\begin{gathered}
g(t)=r(t)+1_{V(t+\Delta) \geq 0} l_{B}(t)+1_{V(t+\Delta t)<0} l_{A}(t) \\
l_{B}(t)=\left(1-\varphi_{B}(t)\right) h_{B}(t)+\left(1-\bar{\varphi}_{B}(t)\right) h_{A}(t)-\left(1-\varphi_{B}(t)-\bar{\varphi}_{B}(t)+\varphi_{A B}(t)\right) \rho_{A B}(t) \sqrt{h_{A}(t) h_{B}(t)} \\
l_{A}(t)=\left(1-\varphi_{A}(t)\right) h_{A}(t)+\left(1-\bar{\varphi}_{A}(t)\right) h_{B}(t)-\left(1-\varphi_{A}(t)-\bar{\varphi}_{A}(t)+\varphi_{A B}(t)\right) \rho_{A B}(t) \sqrt{h_{A}(t) h_{B}(t)}
\end{gathered}
$$


where $1_{Y}$ is an indicator function that is equal to one if $\mathrm{Y}$ is true and zero otherwise, $E\left\{\bullet \mid F_{t}\right\}$ is the expectation conditional on the $F_{t}, r(t)$ is the risk-free short rate, and $\varphi_{i}$ is the recovery rate.

The pricing equation above keeps terms of order $\Delta t$. All higher order terms of $\Delta t$ are omitted. Similarly, we have

$$
V(t+\Delta t)=E\left\{\exp (-g(t+\Delta t) \Delta t) V(t+2 \Delta t) \mid F_{t+\Delta t}\right\}
$$

Note that $\exp (-g(t) \Delta t)$ is $F_{t+\Delta t}$-measurable. By definition, an $F_{t+\Delta t}$-measurable random variable is a random variable whose value is known at time $t+\Delta t$. Based on the taking out what is known and tower properties of conditional expectation, we have

$$
\begin{aligned}
V(t) & =E\left\{\exp (-g(t) \Delta t) V(t+\Delta t) \mid F_{t}\right\}=E\left\{\exp (-g(t) \Delta t) E\left[\exp (-g(t+\Delta t) \Delta t) V(t+2 \Delta t) \mid F_{t+\Delta t}\right] \mid F_{t}\right\} \\
& \left.=E\left\{\exp \left(-\sum_{i=0}^{1} g(t+i \Delta t) \Delta t\right)\right) V(t+2 \Delta t) \mid F_{t}\right\}
\end{aligned}
$$

By recursively deriving from $t$ forward over $T$ where $V(T)=X_{T}$ and taking the limit as $\Delta t$ approaches zero, we obtain

$$
V(t)=E\left\{G(t, T) X_{T} \mid F_{t}\right\}=E\left\{\exp \left[-\int_{t}^{T} g(u) d u\right] X_{T} \mid F_{t}\right\}
$$

We may think of $G(t, T)$ as the bilateral risk-adjusted discount factor and $g(u)$ as the bilateral risk-adjusted short rate. Equation (8) has a general form that applies in a particular situation where we assume that parties $A$ and $B$ have independent default risks, i.e. $\rho_{A B}=0$ and $\varphi_{A B}=0$. Thus, we have:

$$
V(t)=E\left\{\bar{G}(t, T) X_{T} \mid F_{t}\right\}=E\left\{\exp \left[-\int_{t}^{T} \bar{g}(u) d u\right] X_{T} \mid F_{t}\right\}
$$

where

$$
\begin{gathered}
\bar{g}(u)=r(u)+1_{V(u) \geq 0} \bar{l}_{B}(u)+1_{V(u)<0} \bar{l}_{A}(u) \\
\bar{l}_{B}(u)=\left(1-\varphi_{B}(u)\right) h_{B}(u)+\left(1-\bar{\varphi}_{B}(u)\right) h_{A}(u) \\
\bar{l}_{A}(u)=\left(1-\varphi_{A}(u)\right) h_{A}(u)+\left(1-\bar{\varphi}_{A}(u)\right) h_{B}(u)
\end{gathered}
$$

Equation (9) is the same as equation (2.5') in Duffie and Huang (1996). 
In theory, a default may happen at any time, i.e., a risky contract is continuously defaultable. This Continuous Time Risky Valuation Model is accurate but sometimes complex and expensive. For simplicity, people sometimes prefer the Discrete Time Risky Valuation Model that assumes that a default may only happen at some discrete times. A natural selection is to assume that a default may occur only on the payment dates. Fortunately, the level of accuracy for this discrete approximation is well inside the typical bid-ask spread for most applications (see O'Kane and Turnbull (2003)). From now on, we will focus on the discrete setting only, but many of the points we make are equally applicable to the continuous setting.

If we assume that a default may occur only on the payment date, the risky value of the instrument in a discrete-time setting is given by

$$
\begin{aligned}
V(t)= & E\left\{D ( t , T ) \left[1_{X_{T} \geq 0}\left\langle p_{00}(t, T)+\varphi_{B}(T) p_{01}(t, T)+\bar{\varphi}_{B}(T) p_{10}(t, T)+\varphi_{A B}(T) p_{11}(t, T)\right\rangle X_{T} \mid \mathrm{F}_{\mathrm{t}}\right.\right. \\
& \left.\left.+1_{X_{T}<0}\left\langle p_{00}(t, T)+\bar{\varphi}_{A}(T) p_{01}(t, T)+\varphi_{A}(T) p_{10}(t, T)+\varphi_{A B}(T) p_{11}(t, T)\right\rangle X_{T} \mid \mathrm{F}_{\mathrm{t}}\right]\right\} \\
= & E\left[D(t, T)\left(1_{X_{T} \geq 0} k_{B}(t, T)+1_{X_{T}<0} k_{A}(t, T)\right) X_{T} \mid \mathrm{F}_{\mathrm{t}}\right]=E\left(K(t, T) X_{T} \mid \mathrm{F}_{\mathrm{t}}\right)
\end{aligned}
$$

where

$$
\begin{aligned}
k_{B}(t, T)= & p_{B}(t, T) p_{A}(t, T)+\varphi_{B}(T) q_{B}(t, T) p_{A}(t, T)+\bar{\varphi}_{B}(T) p_{B}(t, T) q_{A}(t, T) \\
& +\varphi_{A B}(T) q_{B}(t, T) q_{A}(t, T)+\sigma_{A B}(t, T)\left(1-\varphi_{B}(T)-\bar{\varphi}_{B}(T)+\varphi_{A B}(T)\right) \\
k_{A}(t, T)= & p_{B}(t, T) p_{A}(t, T)+\varphi_{A}(T) q_{A}(t, T) p_{B}(t, T)+\bar{\varphi}_{A}(T) p_{A}(t, T) q_{B}(t, T) \\
& +\varphi_{A B}(T) q_{B}(t, T) q_{A}(t, T)+\sigma_{A B}(t, T)\left(1-\varphi_{A}(T)-\bar{\varphi}_{A}(T)+\varphi_{A B}(T)\right)
\end{aligned}
$$

where $D(t, \tau)$ denotes the stochastic risk-free discount factor at $t$ for the maturity $T$ given by

$$
D(t, T)=\exp \left[-\int_{t}^{T} r(u) d u\right]
$$

We may think of $K(t, T)$ as the risk-adjusted discount factor, and $k_{A}(t, T)$ and $k_{B}(t, T)$ as the adjustment factors. Equation (10) tells us that the bilateral risky price of a single-payment instrument can be expressed as the present value of the payoff discounted by a risk-adjusted discount factor that has a switching-type dependence on the sign of the payoff. 
Equation (10) can be easily extended from one-period to multiple-periods. Suppose that a defaultable instrument has $m$ cash flows. Let the $m$ cash flows be represented as $X_{1}, \ldots, X_{m}$ with payment dates $T_{1}, \ldots, T_{m}$. Each cash flow may be positive or negative. We have the following proposition.

Proposition 1: The risky value of the multiple-payment instrument is given by

$$
V(t)=\sum_{i=1}^{m} E\left[\left(\prod_{j=0}^{i-1} K\left(T_{j}, T_{j+1}\right)\right) X_{i} \mid F_{t}\right]
$$

where $t=T_{0}$ and

$$
K\left(T_{j}, T_{j+1}\right)=D\left(T_{j}, T_{j+1}\right)\left(1_{\left(X_{j+1}+V\left(T_{j+1}\right)\right) \geq 0} k_{B}\left(T_{j}, T_{j+1}\right)+1_{\left(X_{j+1}+V\left(T_{j+1}\right)\right)<0} k_{A}\left(T_{j}, T_{j+1}\right)\right)
$$

where $k_{A}\left(T_{j}, T_{j+1}\right)$ and $k_{B}\left(T_{j}, T_{j+1}\right)$ are defined in Equation (10).

Proof: See the Appendix.

From Proposition 1, we can see that the intermediate values are vital to determine the final price. For a payment interval, the current risky value has a dependence on the future risky value. Only on the final payment date $T_{m}$, the value of the instrument and the maximum amount of information needed to determine the risk-adjusted discount factor are revealed. This type of problem can be best solved by working backwards in time, with the later risky value feeding into the earlier ones, so that the process builds on itself in a recursive fashion, which is referred to as backward induction. The most popular backward induction valuation algorithms are lattice/tree and regression-based Monte Carlo.

\subsection{Risky valuation with collateralization}

Collateralization is the most important and widely used technique in practice to mitigate credit risk. The posting of collateral is regulated by the Credit Support Annex (CSA) that specifies a variety of terms including the threshold, the independent amount, and the minimum transfer amount (MTA), etc. The threshold is the unsecured credit exposure that a party is willing to bear. The minimum transfer amount is the smallest amount of collateral that can be transferred. The independent amount plays the same role as the initial margin (or haircuts). 
In a typical collateral procedure, a financial instrument is periodically marked-to-market and the collateral is adjusted to reflect changes in value. The collateral is called as soon as the mark-to-market (MTM) value rises above the given collateral threshold, or more precisely, above the threshold amount plus the minimum transfer amount. Thus, the collateral amount posted at time $t$ is given by

$$
C(t)=\left\{\begin{array}{lr}
V(t)-H(t) & \text { if } V(t)>H(t) \\
0 & \text { otherwise }
\end{array}\right.
$$

where $H(t)$ is the collateral threshold. In particular, $H(t)=0$ corresponds to full-collateralization ${ }^{2} ; H>0$ represents partial/under-collateralization; and $H<0$ is associated with over-collateralization. Full collateralization becomes increasingly popular at the transaction level. In this paper, we focus on full collateralization only, i.e., $C(t)=V(t)$.

The main role of collateral should be viewed as an improved recovery in the event of a counterparty default. According to Bankruptcy law, if there has been no default, the collateral is returned to the collateral giver by the collateral taker. If a default occurs, the collateral taker possesses the collateral. In other words, collateral does not affect the survival payment; instead, it takes effect on the default payment only.

For a discrete one-period $(t, u)$ economy, the posted collateral at time $t$ is $C(t)=V(t)$. At time $u$, there are several possible states: i) Both $A$ and $B$ survive. The instrument value is equal to the market value $V(u)$; ii) Either or both counterparties $A$ and $B$ default. The instrument value is the future value of the collateral, i.e., $C(u)=V(t) / D(t, u)$ where we consider the time value of money only. Since the majority of the collateral is cash according to ISDA (2012), it is reasonable to consider the time value of money only for collateral assets. The large use of cash means that collateral is both liquid and not subject

\footnotetext{
${ }^{2}$ There are three types of collateralization: Full-collateralization is a process where the posting of collateral is equal to the current MTM value. Partial/under-collateralization is a process where the posting of collateral is less than the current MTM value. Over-collateralization is a process where the posting of collateral is greater than the current MTM value.
} 
to large fluctuations in value. The value of the collateralized instrument at time $t$ is the discounted expectation of all the payoffs and is given by

$$
\begin{aligned}
V(t) & =E\left[D(t, u)\left(p_{00}(t, u) V(u)+p_{01}(t, u) C(u)+p_{10}(t, u) C(u)+p_{11}(t, u) C(u)\right) \mid \mathrm{F}_{\mathrm{t}}\right] \\
& =E\left[D(t, u) p_{00}(t, u) V(u) \mid \mathrm{F}_{\mathrm{t}}\right]+\left[1-E\left(p_{00}(t, u) \mid \mathrm{F}_{\mathrm{t}}\right)\right] V(t)
\end{aligned}
$$

or

$$
V(t)=E\left[D(t, s) p_{00}(t, s) V(s) \mid F_{t}\right] / E\left(p_{00}(t, s) \mid F_{t}\right)
$$

If we assume that default probabilities are uncorrelated with interest rates and payoffs ${ }^{3}$, we have

$$
V(t)=E\left[D(t, s) V(s) \mid F_{t}\right]
$$

Equation (14) is the formula for the risk-free valuation. Thus, we have the following proposition.

Proposition 2: If a bilateral risky instrument is fully collateralized, the risky value of the instrument is equal to the risk-free value, as shown in equation (14).

Since an IRS is a typical bilateral risky contract, Proposition 2 squares with the results of Johannes and Sundaresan (2007), and is also consistent with the current market practice in which market participants commonly assume fully collateralized swaps are risk-free and it is common to build models of swap rates assuming that swaps are free of counterparty risk.

\subsection{Numerical results}

To study the impact of bilateral credit risk, we have selected a new 10-year fixed-for-floating IRS with a quarterly payment frequency. Two counterparties are denoted as $A$ and $B$. Counterparty $A$ pays a fixed rate and counterparty $B$ pays a floating rate. All calculations are from the perspective of party $A$.

The current (spot) market data are shown in Table 2, provided by FinPricing (2019). At the time the contract is entered into, there is no advantage to either party. By definition, a swap rate is a fixed rate

\footnotetext{
${ }^{3}$ Moody's Investor's Service (2000) presents statistics that suggest that the correlations between interest rates, default probabilities, and recovery rates are very small and provides a reasonable comfort level for the uncorrelated assumption.
} 
that makes the market value of a given swap at initiation zero. The risk-free swap rate can be easily calculated as 0.03433 .

Since the payoff of an IRS is determined by interest rates, we need to model the evolution of the floating rates. Interest rate models are based on evolving either short rates, instantaneous forward rates, or market forward rates (e.g., the LIBOR Market Model (LMM)). Since both short rates and instantaneous forward rates are not directly observable in the market, the models based on these rates have difficulties in expressing market views and quotes in term of model parameters, and lack agreement with market valuation formulas for basic derivatives. On the other hand, the object modeled under the LMM is market-observable. It is also consistent with the market standard approach for pricing caps/floors using Black's formula. They are generally considered to have more desirable theoretical calibration properties than short rate or instantaneous forward rate models. Therefore, we choose the LMM lattice proposed by Xiao (2011) for pricing the defaultable IRS. We also implement the Hull-White trinomial tree to verify the results and ensure robustness of the valuation. This paper, however, only reports the results produced by the LMM lattice.

We first assume that i) counterparties $A$ and $B$ have independent default risks; ii) the hazard rates are deterministic; and iii) both parties have a constant recovery of $60 \%$. We use the LMM to evolve the interest rates and then price the risky IRS according to Proposition 1. The risky swap rates are computed and shown in Table 3.

From Table 3, we derive the following conclusions: First, a fixed-rate payer with lower credit quality (higher credit risk) pays a higher fixed rate. Second, a credit spread of about 100 basis points translates into a swap spread of about 1.3 basis points. Finally, the credit impact on swap rates is approximately linear within the range of normally encountered credit quality. This confirms the findings of Duffie and Huang (1996). Intuitively, a risk-free floating-rate payer demands a higher fixed rate if the fixed-rate payer has a lower credit score. 
We next present some new results. Assume that party $A$ has an 'A+300bps' credit quality, i.e., a '300 basis points' parallel shift in the A-rated credit spreads, and party $B$ has an 'A' credit quality. The risky swap rate with asymmetric credit qualities is calculated as 0.03436 .

Assume $\varphi_{A B}=0.5$. The effect of the default correlation $\rho_{A B}$ on swap rate is shown in Figure 1 . We can draw the following conclusions from the results: First, the counterparty default correlation and the swap rates have a negative relation, i.e., a negative sensitivity of swap rates to changes in counterparty default correlation is obtained. Second, the graph suggests an almost linear relationship between the swap rates and the default correlation. Finally, the impact of the default correlation is modest (e.g., in the range of $[-2,2]$ basis points).

Bilateral credit risk modeling is probably the simplest example involving default dependency, but it shows several essential features for modeling correlated credit risk, which will help the reader better understand the increasingly complex cases in the following section.

\section{Pricing Financial Instruments Subject to Multilateral Credit Risk}

The interest in the financial industry for the modeling and pricing of multilateral defaultable instruments arises mainly in two respects: in the management of credit risk at a portfolio level and in the valuation of credit derivatives. Central to the pricing and risk management of credit derivatives and credit risk portfolios is the issue of default relationships.

Let us discuss the three-party case first. A CDS is a good example of a trilateral defaultable instrument where the three parties are counterparties $A, B$ and reference entity $C$. In a standard CDS contract one party purchases credit protection from another party, to cover the loss of the face value of a reference entity following a credit event. The protection buyer makes periodic payments to the seller until the maturity date or until a credit event occurs. A credit event usually requires a final accrual payment by the buyer and a loss protection payment by the protection seller. The protection payment is equal to the 
difference between par and the price of the cheapest to deliver (CTD) asset of the reference entity on the face value of the protection.

A CDS is normally used to transfer the credit risk of a reference entity between two counterparties. The contract reduces the credit risk of the reference entity but gives rise to another form of risk: counterparty risk. Since the dealers are highly concentrated within a small group, any of them may be too big to fail. The interconnected nature, with dealers being tied to each other through chains of OTC derivatives, results in increased contagion risk. Due to its concentration and interconnectedness, the CDS market seems to pose a systemic risk to financial market stability. In fact, the CDS is blamed for playing a pivotal role in the collapse of Lehman Brothers and the disintegration of AIG.

For years, a widespread practice in the market has been to mark CDS to market without taking the counterparty risk into account. The realization that even the most prestigious investment banks could go bankrupt has shattered the foundation of the practice. It is wiser to face frankly the real complexities of pricing a CDS than to indulge in simplifications that have proved treacherous. For some time now it has been realized that, in order to value a CDS properly, counterparty effects have to be taken into account.

The default indicator $Y_{j}$ for firm $j(j=A$ or $B$ or $C$ ) follows a Bernoulli distribution, which takes value 1 with default probability $q_{j}$, and value 0 with survival probability $p_{j}$. The joint probability representations of a trivariate Bernoulli distribution (see Teugels (1990)) are given by

$$
\begin{aligned}
& p_{000}:=P\left(Y_{A}=0, Y_{B}=0, Y_{C}=0\right)=p_{A} p_{B} p_{C}+p_{C} \sigma_{A B}+p_{B} \sigma_{A C}+p_{A} \sigma_{B C}-\theta_{A B C} \\
& p_{100}:=P\left(Y_{A}=1, Y_{B}=0, Y_{C}=0\right)=q_{A} p_{B} p_{C}-p_{C} \sigma_{A B}-p_{B} \sigma_{A C}+q_{A} \sigma_{B C}+\theta_{A B C} \\
& p_{010}:=P\left(Y_{A}=0, Y_{B}=1, Y_{C}=0\right)=p_{A} q_{B} p_{C}-p_{C} \sigma_{A B}+q_{B} \sigma_{A C}-p_{A} \sigma_{B C}+\theta_{A B C} \\
& p_{001}:=P\left(Y_{A}=0, Y_{B}=0, Y_{C}=1\right)=p_{A} p_{B} q_{C}+q_{C} \sigma_{A B}-p_{B} \sigma_{A C}-p_{A} \sigma_{B C}+\theta_{A B C} \\
& p_{110}:=P\left(Y_{A}=1, Y_{B}=1, Y_{C}=0\right)=q_{A} q_{B} p_{C}+p_{C} \sigma_{A B}-q_{B} \sigma_{A C}-q_{A} \sigma_{B C}-\theta_{A B C} \\
& p_{101}:=P\left(Y_{A}=1, Y_{B}=0, Y_{C}=1\right)=q_{A} p_{B} q_{C}-q_{C} \sigma_{A B}+p_{B} \sigma_{A C}-q_{A} \sigma_{B C}-\theta_{A B C} \\
& p_{011}:=P\left(Y_{A}=0, Y_{B}=1, Y_{C}=1\right)=p_{A} q_{B} q_{C}-q_{C} \sigma_{A B}-q_{B} \sigma_{A C}+p_{A} \sigma_{B C}-\theta_{A B C}
\end{aligned}
$$




$$
p_{111}:=P\left(Y_{A}=1, Y_{B}=1, Y_{C}=1\right)=q_{A} q_{B} q_{C}+q_{C} \sigma_{A B}+q_{B} \sigma_{A C}+q_{A} \sigma_{B C}+\theta_{A B C}
$$

where

$$
\theta_{A B C}:=E\left(\left(Y_{A}-q_{A}\right)\left(Y_{B}-q_{B}\right)\left(Y_{C}-q_{C}\right)\right)
$$

Equation (15) tells us that the joint probability distribution of three defaultable parties depends not only on the bivariate statistical relationships of all pair-wise combinations (e.g., $\sigma_{i j}$ ) but also on the trivariate statistical relationship (e.g., $\theta_{A B C}$ ). $\theta_{A B C}$ was first defined by Deardorff (1982) as comvariance, who use it to correlate three random variables that are the value of commodity net imports/exports, factor intensity, and factor abundance in international trading.

We introduce the concept of comvariance into credit risk modeling arena to exploit any statistical relationship among multiple random variables. Furthermore, we define a new statistic, comrelation, as a scaled version of comvariance (just like correlation is a scaled version of covariance) as follows:

Definition 1: For three random variables $X_{A}, X_{B}$, and $X_{C}$, let $\mu_{A}, \mu_{B}$, and $\mu_{C}$ denote the means of $X_{A}, X_{B}$, and $X_{C}$. The comrelation of $X_{A}, X_{B}$, and $X_{C}$ is defined by

$$
\zeta_{A B C}=\frac{E\left[\left(X_{A}-\mu_{A}\right)\left(X_{B}-\mu_{B}\right)\left(X_{C}-\mu_{C}\right)\right]}{\sqrt[3]{E\left|X_{A}-\mu_{A}\right|^{3} \times E\left|X_{B}-\mu_{B}\right|^{3} \times E\left|X_{C}-\mu_{C}\right|^{3}}}
$$

According to the Holder inequality, we have

$$
\left|E\left(\left(X_{A}-\mu_{A}\right)\left(X_{B}-\mu_{B}\right)\left(X_{C}-\mu_{C}\right)\right)\right| \leq E\left|\left(X_{A}-\mu_{A}\right)\left(X_{B}-\mu_{B}\right)\left(X_{C}-\mu_{C}\right)\right| \leq \sqrt[3]{E\left|X_{A}-\mu_{A}\right|^{3} \times E\left|X_{B}-\mu_{B}\right|^{3} \times E\left|X_{C}-\mu_{C}\right|^{3}}
$$

Obviously, the comrelation is in the range of $[-1,1]$. Given the comrelation, Equation (15i) can be rewritten as

$$
\begin{aligned}
\theta_{A B C} & :=E\left(\left(Y_{A}-q_{A}\right)\left(Y_{B}-q_{B}\right)\left(X_{C}-q_{C}\right)\right)=\zeta_{A B C} \sqrt[3]{E\left|Y_{A}-q_{A}\right|^{3} \times E\left|Y_{B}-q_{B}\right|^{3} \times E\left|Y_{C}-q_{C}\right|^{3}} \\
& =\zeta_{A B C} \sqrt[3]{\left|p_{A} q_{A}\left(p_{A}^{2}+q_{A}^{2}\right) p_{B} q_{B}\left(p_{B}^{2}+q_{B}^{2}\right) p_{C} q_{C}\left(p_{C}^{2}+q_{C}^{2}\right)\right|}
\end{aligned}
$$

where $E\left(Y_{j}\right)=q_{j}$ and $E\left|Y_{j}-q_{j}\right|^{3}=p_{j} q_{j}\left(p_{j}^{2}+q_{j}^{2}\right), j=A, B$, or $C$.

If we have a series of $n$ measurements of $X_{A}, X_{B}$, and $X_{C}$ written as $x_{A i}, x_{B i}$ and $x_{C i}$ where $i=$ $1,2, \ldots, n$, the sample comrelation coefficient can be obtained as: 


$$
\zeta_{A B C}=\frac{\sum_{i=1}^{n}\left(x_{A i}-\mu_{A}\right)\left(x_{B i}-\mu_{B}\right)\left(x_{C i}-\mu_{C}\right)}{\sqrt[3]{\sum_{i=1}^{n}\left|x_{A i}-\mu_{A}\right|^{3} \times \sum_{i=1}^{n}\left|x_{B i}-\mu_{B}\right|^{3} \times \sum_{i=1}^{n}\left|x_{C i}-\mu_{C}\right|^{3}}}
$$

More generally, we define the comrelation in the context of $n$ random variables as

Definition 2: For $n$ random variables $X_{1}, X_{2}, \ldots, X_{n}$, let $\mu_{i}$ denote the mean of $X_{i}$ where $i=1, . ., n$. The comrelation of $X_{1}, X_{2}, \ldots, X_{n}$ is defined as

$$
\zeta_{12 \ldots n}=\frac{E\left[\left(X_{1}-\mu_{1}\right)\left(X_{2}-\mu_{2}\right) \cdots\left(X_{n}-\mu_{n}\right)\right]}{\sqrt[n]{E\left|X_{1}-\mu_{1}\right|^{n} \times E\left|X_{2}-\mu_{2}\right|^{n} \cdots \times E\left|X_{n}-\mu_{n}\right|^{n}}}
$$

The correlation is just a specific case of the comrelation where $n=2$. Again, the comrelation $\zeta_{12 \ldots n}$ is in the range of $[-1,1]$ according to the Holder inequality.

\subsection{Risky valuation without collateralization}

Recovery assumptions are important for pricing credit derivatives. If the reference entity under a CDS contract defaults, the best assumption, as pointed out by J. P. Morgan (1999), is that the recovered value equals the recovery rate times the face value plus accrued interest ${ }^{4}$. In other words, the recovery of par value assumption is a better fit upon the default of the reference entity, whereas the recovery of market value assumption is a more suitable choice in the event of a counterparty default.

Let valuation date be $t$. Suppose that a CDS has $m$ scheduled payments. Let each payment be represented as $X_{i}=-s N \delta\left(T_{i-1}, T_{i}\right)$ with payment dates $T_{1}, \ldots, T_{m}$ where $i=1,,,, m, \delta\left(T_{i-1}, T_{i}\right)$ denotes the accrual factor for period $\left(T_{i-1}, T_{i}\right), N$ denotes the notional/principal, and $s$ denotes the CDS premium. Party $A$ pays the premium/fee to party $B$ if reference entity $C$ does not default. In return, party $B$ agrees to pay the protection amount to party $A$ if reference entity $C$ defaults before the maturity. We have the following proposition.

Proposition 3: The value of the multiple-payment CDS is given by

\footnotetext{
${ }^{4}$ In the market, there is an average accrual premium assumption, i.e., the average accrued premium is half the full premium due to be paid at the end of the premium.
} 


$$
V(t)=\sum_{i=1}^{m} E\left\lfloor\left(\prod_{j=0}^{i-1} O\left(T_{j}, T_{j+1}\right)\right) X_{i} \mid \mathrm{F}_{\mathrm{t}}\right\rfloor+\sum_{i=1}^{m} E\left[\left(\prod_{j=0}^{i-2} O\left(T_{j}, T_{j+1}\right)\right) \Omega\left(T_{i-1}, T_{i}\right) R\left(T_{i-1}, T_{i}\right) \mid \mathrm{F}_{\mathrm{t}}\right\rfloor
$$

where $t=T_{0}$ and

$$
\begin{aligned}
& \left.O\left(T_{j}, T_{j+1}\right)=1_{\left(V\left(T_{j+1}\right)+X\right.}\right)_{j+1}{ }_{0} \phi_{B}\left(T_{j}, T_{j+1}\right)+1_{\left(V\left(T_{j+1}\right)+X_{j+1}\right)}{ }_{k 0} \phi_{A}\left(T_{j}, T_{j+1}\right) \\
& \phi_{A}\left(T_{j}, T_{j+1}\right)=\left\{p_{A}\left(T_{j}, T_{j+1}\right) p_{B}\left(T_{j}, T_{j+1}\right) p_{C}\left(T_{j}, T_{j+1}\right)+q_{A}\left(T_{j}, T_{j+1}\right) p_{B}\left(T_{j}, T_{j+1}\right) p_{C}\left(T_{j}, T_{j+1}\right) \varphi_{A}\left(T_{j+1}\right)\right. \\
& +p_{A}\left(T_{j}, T_{j+1}\right) q_{B}\left(T_{j}, T_{j+1}\right) p_{C}\left(T_{j}, T_{j+1}\right) \bar{\varphi}_{A}\left(T_{j+1}\right)+q_{A}\left(T_{j}, T_{j+1}\right) q_{B}\left(T_{j}, T_{j+1}\right) p_{C}\left(T_{j}, T_{j+1}\right) \varphi_{A B}\left(T_{j+1}\right) \\
& +p_{C}\left(T_{j}, T_{j+1}\right) \sigma_{A B}\left(T_{j}, T_{j+1}\right)\left(1-\varphi_{A}\left(T_{j+1}\right)-\bar{\varphi}_{A}\left(T_{j+1}\right)+\varphi_{A B}\left(T_{j+1}\right)\right) \\
& +\sigma_{A C}\left(T_{j}, T_{j+1}\right)\left[p_{B}\left(T_{j}, T_{j+1}\right)\left(1-\varphi_{A}\left(T_{j+1}\right)\right)+q_{B}\left(T_{j}, T_{j+1}\right)\left(\bar{\varphi}_{A}\left(T_{j+1}\right)-\varphi_{A B}\left(T_{j+1}\right)\right)\right] \\
& +\sigma_{B C}\left(T_{j}, T_{j+1}\right)\left[p_{A}\left(T_{j}, T_{j+1}\right)\left(1-\bar{\varphi}_{A}\left(T_{j+1}\right)\right)+q_{A}\left(T_{j}, T_{j+1}\right)\left(\varphi_{A}\left(T_{j+1}\right)-\varphi_{A B}\left(T_{j+1}\right)\right)\right] \\
& \left.+\theta_{A B C}\left(T_{j}, T_{j+1}\right)\left(-1+\bar{\varphi}_{A}\left(T_{j+1}\right)-\varphi_{A B}\left(T_{j+1}\right)+\varphi_{A}\left(T_{j+1}\right)\right)\right\} D\left(T_{j}, T_{j+1}\right) \\
& \phi_{B}\left(T_{j}, T_{j+1}\right)=\left\{p_{A}\left(T_{j}, T_{j+1}\right) p_{B}\left(T_{J}, T_{j+1}\right) p_{C}\left(T_{j}, T_{j+1}\right)+q_{A}\left(T_{j}, T_{j+1}\right) p_{B}\left(T_{j}, T_{j+1}\right) p_{C}\left(T_{j}, T_{j+1}\right) \bar{\varphi}_{B}\left(T_{j+1}\right)\right. \\
& +p_{A}\left(T_{j}, T_{j+1}\right) q_{B}\left(T_{j}, T_{j+1}\right) p_{C}\left(T_{j}, T_{j+1}\right) \varphi_{B}\left(T_{j+1}\right)+q_{A}\left(T_{j}, T_{j+1}\right) q_{B}\left(T_{j}, T_{j+1}\right) p_{C}\left(T_{j}, T_{j+1}\right) \varphi_{A B}\left(T_{j+1}\right) \\
& +p_{C}\left(T_{j}, T_{j+1}\right) \sigma_{A B}\left(T_{j}, T_{j+1}\right)\left(1-\varphi_{B}\left(T_{j+1}\right)-\bar{\varphi}_{B}\left(T_{j+1}\right)+\varphi_{A B}\left(T_{j+1}\right)\right) \\
& +\sigma_{A C}\left(T_{j}, T_{j+1}\right)\left[p_{B}\left(T_{j}, T_{j+1}\right)\left(1-\bar{\varphi}_{B}\left(T_{j+1}\right)\right)+q_{B}\left(T_{j}, T_{j+1}\right)\left(\varphi_{B}\left(T_{j+1}\right)-\varphi_{A B}\left(T_{j+1}\right)\right)\right] \\
& +\sigma_{B C}\left(T_{j}, T_{j+1}\right)\left[p_{A}\left(T_{j}, T_{j+1}\right)\left(1-\varphi_{B}\left(T_{j}\right)\right)+q_{A}\left(T_{j}, T_{j+1}\right)\left(\bar{\varphi}_{B}\left(T_{j+1}\right)-\varphi_{A B}\left(T_{j+1}\right)\right)\right] \\
& \left.+\theta\left(T_{j}, T_{j+1}\right)\left(-1+\bar{\varphi}_{B}\left(T_{j+1}\right)-\varphi_{A B}\left(T_{j+1}\right)+\varphi_{B}\left(T_{j+1}\right)\right)\right\} D\left(T_{j}, T_{j+1}\right) \\
& \Omega\left(T_{j}, T_{j+1}\right)=\left\{p_{A}\left(T_{j}, T_{j+1}\right) p_{B}\left(T_{j}, T_{j+1}\right) q_{C}\left(T_{j}, T_{j+1}\right)+q_{A}\left(T_{j}, T_{j+1}\right) p_{B}\left(T_{j}, T_{j+1}\right) q_{C}\left(T_{j}, T_{j+1}\right) \bar{\varphi}_{B}\left(T_{j+1}\right)\right. \\
& +p_{A}\left(T_{j}, T_{j+1}\right) q_{B}\left(T_{j}, T_{j+1}\right) q_{C}\left(T_{j}, T_{j+1}\right) \varphi_{B}\left(T_{j+1}\right)+q_{A}\left(T_{j}, T_{j+1}\right) q_{B}\left(T_{j}, T_{j+1}\right) q_{C}\left(T_{j}, T_{j+1}\right) \varphi_{A B}\left(T_{j+1}\right) \\
& +q_{C}\left(T_{j}, T_{j+1}\right) \sigma_{A B}\left(T_{j}, T_{j+1}\right)\left(1-\varphi_{B}\left(T_{j+1}\right)-\bar{\varphi}_{B}\left(T_{j+1}\right)+\varphi_{A B}\left(T_{j+1}\right)\right) \\
& -\sigma_{A C}\left(T_{j}, T_{j+1}\right)\left[p_{B}\left(T_{j}, T_{j+1}\right)\left(1-\bar{\varphi}_{B}\left(T_{j+1}\right)\right)+q_{B}\left(T_{j}, T_{j+1}\right)\left(\varphi_{B}\left(T_{j+1}\right)-\varphi_{A B}\left(T_{j+1}\right)\right)\right] \\
& -\sigma_{B C}\left(T_{j}, T_{j+1}\right)\left[p_{A}\left(T_{j}, T_{j+1}\right)\left(1-\varphi_{B}\left(T_{j+1}\right)\right)+q_{A}\left(T_{j}, T_{j+1}\right)\left(\bar{\varphi}_{B}\left(T_{j+1}\right)-\varphi_{A B}\left(T_{j+1}\right)\right)\right] \\
& \left.+\theta_{A B C}\left(T_{j}, T_{j+1}\right)\left(1-\bar{\varphi}_{B}\left(T_{j+1}\right)+\varphi_{A B}\left(T_{j+1}\right)-\varphi_{B}\left(T_{j+1}\right)\right)\right\} D\left(T_{j}, T_{j+1}\right)
\end{aligned}
$$

where $R\left(T_{j}, T_{j+1}\right)=\left(N\left(1-\varphi_{C}\left(T_{j+1}\right)\right)-\alpha\left(T_{j}, T_{j+1}\right)\right), \alpha\left(T_{j}, T_{j+1}\right)=s N \delta\left(T_{S}, T\right) / 2$, and $X_{i}=-s N \delta\left(T_{j}, T_{j+1}\right)$.

Proof: See the Appendix.

We may think of $O(t, T)$ as the risk-adjusted discount factor for the premium and $\Omega(t, T)$ as the risk-adjusted discount factor for the default payment. Proposition 3 says that the pricing process of a multiple-payment instrument has a backward nature since there is no way of knowing which risk-adjusted discounting rate should be used without knowledge of the future value. Only on the maturity date, the value of an instrument and the decision strategy are clear. Therefore, the evaluation must be done in a backward fashion, working from the final payment date towards the present. This type of valuation process is referred to as backward induction. 
Proposition 3 provides a general form for pricing a CDS. Applying it to a particular situation in which we assume that counterparties $A$ and $B$ are default-free, i.e., $p_{j}=1, q_{j}=0, \rho_{k l}=0$, and $\varsigma_{A B C}=0$, where $j=A$ or $B$ and $k, l=A, B$, or $C$, we derive the following corollary.

Corollary 1: If counterparties $A$ and $B$ are default-free, the value of the multiple-payment CDS is given by

$$
\begin{aligned}
V(t) & =\sum_{i=1}^{m} E\left[\left(\prod_{j=0}^{i-1} O\left(T_{j}, T_{j+1}\right)\right) X_{i} \mid \mathrm{F}_{\mathrm{t}}\right]+\sum_{i=1}^{m} E\left[\left(\prod_{j=0}^{i-2} O\left(T_{j}, T_{j+1}\right)\right) \Omega\left(T_{i-1}, T_{i}\right) R\left(T_{i-1}, T_{i}\right) \mid \mathrm{F}_{\mathrm{t}}\right] \\
& =\sum_{i=1}^{m} E\left[D\left(t, T_{i}\right) p_{C}\left(t, T_{i}\right) X_{i} \mid \mathrm{F}_{\mathrm{t}}\right]+\sum_{i=1}^{m} E\left[D\left(t, T_{i}\right) p_{C}\left(t, T_{i-1}\right) q_{C}\left(T_{i-1}, T_{i}\right) R\left(T_{i-1}, T_{i}\right) \mid \mathrm{F}_{\mathrm{t}}\right]
\end{aligned}
$$

where $O\left(T_{i-1}, T_{i}\right)=D\left(T_{i-1}, T_{i}\right) p_{C}\left(T_{i-1}, T_{i}\right) ; \Omega\left(T_{i-1}, T_{i}\right)=D\left(T_{i-1}, T_{i}\right) q_{C}\left(T_{i-1}, T_{i}\right)$.

The proof of this corollary becomes straightforward according to Proposition 3 by setting $\rho_{k l}=0$, $\varphi_{A B}=0, \varsigma_{A B C}=0, p_{j}=1, q_{j}=0, p_{C}\left(t, T_{i}\right)=\prod_{g=0}^{i-1} p\left(T_{g}, T_{g+1}\right)$, and $D\left(t, T_{i}\right)=\prod_{g=0}^{i-1} D\left(T_{g}, T_{g+1}\right)$.

If we further assume that the discount factor and the default probability of the reference entity are uncorrelated and the recovery rate $\varphi_{C}$ is constant, we have

Corollary 2: Assume that i) counterparties A and B are default-free, ii) the discount factor and the default probability of the reference entity are uncorrelated; iii) the recovery rate $\varphi_{C}$ is constant; the value of the multiple-payment CDS is given by

$$
V(t)=\sum_{i=1}^{m} P\left(t, T_{i}\right) \bar{p}_{C}\left(t, T_{i-1}\right) \bar{q}_{C}\left(T_{i-1}, T_{i}\right)\left(N\left(1-\varphi_{C}\right)-\alpha\left(T_{i-1}, T_{i}\right)\right)-\sum_{i=1}^{m} P\left(t, T_{i}\right) \bar{p}_{c}\left(t, T_{i}\right) s N \delta\left(T_{i-1}, T_{i}\right)
$$

where $P\left(t, T_{i}\right)=E\left[D\left(t, T_{i}\right) \mid F_{t}\right]$ denotes the bond price, $\bar{p}_{c}\left(t, T_{i}\right)=E\left[p_{c}\left(t, T_{i}\right) \mid F_{t}\right], \bar{q}_{c}\left(t, T_{i}\right)=1-\bar{p}_{c}\left(t, T_{i}\right)$, $\bar{p}\left(t, T_{i-1}\right) \bar{q}\left(T_{i-1}, T_{i}\right)=\bar{p}\left(t, T_{i-1}\right)-\bar{p}\left(t, T_{i}\right)$.

This corollary is easily proved according to Corollary 1 by setting $E\left[X Y \mid F_{t}\right]=E\left[X \mid F_{t}\right] E\left[Y \mid F_{t}\right]$ when $X$ and $Y$ are uncorrelated. Corollary 2 is the formula for pricing CDS in the market.

Our methodology can be extended to the cases where the number of parties $n \geq 4$. A generating function for the (probability) joint distribution (see details in Teugels (1990)) of $n$-variate Bernoulli can be expressed as

$$
p^{(n)}=\left[\begin{array}{cc}
p_{n} & -1 \\
q_{n} & 1
\end{array}\right] \otimes\left[\begin{array}{cc}
p_{n-1} & -1 \\
q_{n-1} & 1
\end{array}\right] \otimes \cdots \otimes\left[\begin{array}{cc}
p_{1} & -1 \\
q_{1} & 1
\end{array}\right] \sigma^{(n)}
$$


where $\otimes$ denotes the Kronecker product; $p^{(n)}=\left\{p_{k}^{(n)}\right\}$ and $\sigma^{(n)}=\left\{\sigma_{k}^{(n)}\right\}$ are vectors containing $2^{n}$ components: $p_{k}^{(n)}=p_{k_{1}, k_{2}, \ldots, k_{n}}, k=1+\sum_{i=1}^{n} k_{i} 2^{i-1}, k_{i} \in\{0,1\} ; \sigma_{k}^{(n)}=\sigma_{k_{1}, k_{2}, \ldots, k_{n}}=E\left(\prod_{i=1}^{n}\left(Y_{i}-q_{i}\right)^{k_{i}}\right)$.

\subsection{Risky valuation with collateralization}

According to the ISDA (2012), almost all CDSs are fully collateralized. Many people believe that full collateralization can eliminate counterparty risk completely for CDS.

Collateral posting regimes are originally designed and utilized for bilateral risk products, e.g., IRS, but there are many reasons to be concerned about the success of collateral posting in offsetting the risks of CDS contracts. First, the values of CDS contracts tend to move very suddenly with big jumps, whereas the price movements of IRS contracts are far smoother and less volatile than CDS prices. Second, CDS spreads can widen very rapidly. The amount of collateral that one party is required to provide at short notice may, in some cases, be close to the notional amount of the CDS and may therefore exceed that party's short-term liquidity capacity, thereby triggering a liquidity crisis. Third, CDS contracts have many more risk factors than IRS contracts.

We assume that a CDS is fully collateralized, i.e., the posting of collateral is equal to the amount of the current MTM value: $C(t)=V(t)$. For a discrete one-period $(t, u)$ economy, there are several possible states at time $u$ : i) $A, B$, and $C$ survive with probability $p_{000}$. The instrument value is equal to the market value $V(u)$; ii) $A$ and $B$ survive, but $C$ defaults with probability $p_{001}$. The instrument value is the default payment $R(u)$; iii) For the remaining cases, either or both counterparties $A$ and $B$ default. The instrument value is the future value of the collateral $V(t) / D(t, u)$ (Here we consider the time value of money only). The value of the collateralized instrument at time $t$ is the discounted expectation of all the payoffs and is given by

$$
\begin{aligned}
V(t)= & E\left\{D ( t , u ) \left[p_{000}(t, u) V(u)+p_{001}(t, u) R(u)\right.\right. \\
& \left.\left.+\left(p_{100}(t, u)+p_{010}(t, u)+p_{110}(t, u)+p_{101}(t, u)+p_{011}(t, u)+p_{111}(t, u)\right) V(t) / D(t, u)\right] \mid \mathrm{F}_{\mathrm{t}}\right\} \\
= & E\left\{\left[D(t, u)\left(p_{000}(t, u) V(s)+p_{001}(t, u) R(u)\right)+\left(1-p_{000}(t, u)-p_{001}(t, u)\right) V(t)\right] \mid \mathrm{F}_{\mathrm{t}}\right\}
\end{aligned}
$$

or 


$$
\begin{aligned}
& E\left[\left(p_{A}(t, u) p_{B}(t, u)+\sigma_{A B}(t, u)\right) \mid F_{t}\right] V(t) \\
&= E\left\{D(t, u)\left(p_{C}(t, u) V(u)+q_{C}(t, u) R(u)\right)\left(p_{A}(t, u) p_{B}(t, u)+\sigma_{A B}(t, u)\right)\right. \\
&\left.\left.+D(t, u)(V(u)-R(u))\left(p_{B}(t, u) \sigma_{A C}(t, u)+p_{A}(t, u) \sigma_{B C}(t, u)-\theta_{A B C}(t, u)\right)\right] F_{t}\right\}
\end{aligned}
$$

If we assume that $\left(p_{A}(t, u) p_{B}(t, u)+\sigma_{A B}(t, u)\right)$ and $D(t, u)\left(p_{C}(t, u) V(u)+q_{C}(t, u) R(u)\right)$ are uncorrelated, we have

$$
V(t)=V^{F}(t)+\xi_{A B C}(t, u) / \psi_{A B}(t, u)
$$

where

$$
\begin{gathered}
V^{F}(t)=E\left\{D(t, u)\left[p_{C}(t, u) V(u)+q_{C}(t, u) R(u)\right] \mid F_{t}\right\} \\
\psi_{A B}(t, u)=E\left\{\left[p_{A}(t, u) p_{B}(t, u)+\sigma_{A B}(t, u)\right] \mid F_{t}\right\} \\
\xi_{A B C}(t, u)=E\left\{\left[D(t, u)\left(p_{B}(t, u) \sigma_{A C}(t, u)+p_{A}(t, u) \sigma_{B C}(t, u)-\theta_{A B C}(t, u)\right)(V(u)-R(u))\right] \mid F_{t}\right\}
\end{gathered}
$$

The first term $V^{F}(t)$ in equation (26) is the counterparty-risk-free value of the CDS and the second term is the exposure left over under full collateralization, which can be substantial.

Proposition 4: If a CDS is fully collateralized, the risky value of the CDS is NOT equal to the counterparty-risk-free value, as shown in equation (26).

Proposition 4 or equation (26) provides a theoretical explanation for the failure of full collateralization in the CDS market. It tells us that under full collateralization the risky value is in general not equal to the counterparty-risk-free value except in one of the following situations: i) the market value is equal to the default payment, i.e., $V(u)=R(u)$; ii) firms $A, B$, and $C$ have independent credit risks, i.e., $\rho_{i j}=0$ and $\varsigma_{A B C}=0$; or iii) $p_{B} \sigma_{A C}+p_{A} \sigma_{B C}=\theta_{A B C}$.

\subsection{Numerical results}

Our goal in this subsection is to study the quantitative relationship between the CDS premium and the credit qualities of the counterparties and reference entity, including the default correlations and comrelation in a CDS contract.

In our study, we choose a new 5-year CDS with a quarterly payment frequency. Two counterparties are denoted as $A$ and $B$. Counterparty $A$ buys a protection from counterparty $B$. All 
calculations are from the perspective of party $A$. By definition, a breakeven CDS spread is a premium that makes the market value of a given CDS at inception zero. Assume that the reference entity $C$ has an "A $+200 \mathrm{bps"}$ credit quality throughout this subsection. The 5-year counterparty-risk-free CDS premium is 0.027 (equals the 5-year ' $A$ ' rated CDS spread in Table 2 plus 200 basis points).

Since the payoffs of a CDS are mainly determined by credit events, we need to characterize the evolution of the hazard rates. Here we choose the Cox-Ingersoll-Ross (CIR) model. The CIR process has been widely used in the literature of credit risk and is given by

$$
d h_{t}=a\left(b-h_{t}\right) d t+\sigma \sqrt{h_{t}} d W_{t}
$$

where $a$ denotes the mean reversion speed, $b$ denotes the long-term mean, and $\sigma$ denotes the volatility.

The calibrated parameters are shown in table 4 . We assume that interest rates are deterministic and select the regression-based Monte-Carlo simulation (see Longstaff and Schwartz (2001)) to perform risky valuation.

We first assume that counterparties $A, B$, and reference entity $C$ have independent default risks, i.e., $\rho_{A B}=\rho_{A C}=\rho_{B C}=\varphi_{A B}=\zeta_{A B C}=0$, and examine the following cases: i) $B$ is risk-free and $A$ is risky; and ii) $A$ is risk-free and $B$ is risky. We simulate the hazard rates using the CIR model and then determine the appropriate discount factors according to Proposition 3. Finally we calculate the prices via the regression-based Monte-Carlo method. The results are shown in Table 5 and 6.

From table 5 and 6 , we find that a credit spread of about 100 basis points maps into a CDS premium of about 0.4 basis points for counterparty $A$ and about -0.7 basis points for counterparty $B$. The credit impact on the CDS premia is approximately linear. As would be expected, i) the dealer's credit quality has a larger impact on CDS premia than the investor's credit quality; ii) the higher the investor's credit risk, the higher the premium that the dealer charges; iii) the higher the dealer's credit risk, the lower the premium that the dealer asks. Without considering default correlations and comrelations, we find that, in general, the impact of counterparty risk on CDS premia is relatively small. This is in line with the empirical findings of Arora, Gandhi, and Longstaff (2009). 
Next, we study the sensitivity of CDS premia to changes in the joint credit quality of associated parties. Sensitivity analysis is a very popular way in finance to find out how the value and risk of an instrument/portfolio changes if risk factors change. One of the simplest and most common approaches involves changing one factor at a time to see what effect this produces on the output. We are going to examine the impacts of the default correlations $\rho_{A B}, \rho_{A C}, \rho_{B C}$, and the comrelation $\zeta_{A B C}$ separately. Assume that party $A$ has an 'A+100bps' credit quality and party $B$ has an 'A' credit quality. The 5-year risky CDS premium is calculated as 0.02703 .

Assume $\varphi_{A B}=0.5$. The impact diagrams of the default correlations and comrelation are shown in Figure 2. From this graph, we can draw the following conclusions: First, the CDS premium and the default correlations/comrelation have a negative relation. Intuitively, a protection seller who is positively correlated with the reference entity (a wrong way risk) should charge a lower premium for selling credit protection. Next, the impacts of the default correlations and comrelation are approximately linear. Finally, the sensitivity slopes of the CDS premium to the default correlations and comrelation are -0.06 to $\rho_{A B}$; 0.09 to $\rho_{A C} ;-53$ to $\rho_{B C}$; and -14 to $\zeta_{A B C}$. Slope measures the rate of change in the premium as a result of a change in the default dependence. For instance, a slope of -53 implies that the CDS premium would have to decrease by 53 basis points when a default correlation/comrelation changes from 0 to 1 .

As the absolute value of the slope increases, so does the sensitivity. The results illustrate that $\rho_{B C}$ has the largest effect on CDS premia. The second biggest one is $\zeta_{A B C}$. The impacts of $\rho_{A B}$ and $\rho_{A C}$ are very small. In particular, the effect of the comrelation is substantial and has never been studies before. A natural intuition to have on CDS is that the party buying default protection should worry about the default correlations and comrelation.

\section{Conclusion}

This article presents a new valuation framework for pricing financial instruments subject to credit risk. In particular, we focus on modeling default relationships. Some well-known risky valuation models 
in the market can be viewed as special cases of this framework, when the default dependencies are ignored.

To capture the default relationships among more than two defaultable entities, we introduce a new statistic: comrelation, an analogue to correlation for multiple variables, to exploit any multivariate statistical relationship. Our research shows that accounting for default correlations and comrelations becomes important, especially under market stress. The existing valuation models in the credit derivatives market, which take into account only pair-wise default correlations, may underestimate credit risk and may be inappropriate.

We study the sensitivity of the price of a defaultable instrument to changes in the joint credit quality of the parties. For instance, our analysis shows that the effect of default dependence on CDS premia from large to small is the correlation between the protection seller and the reference entity, the comrelation, the correlation between the protection buyer and the reference entity, and the correlation between the protection buyer and the protection seller.

The model shows that a fully collateralized swap is risk-free, while a fully collateralized CDS is not equivalent to a risk-free one. Therefore, we conclude that collateralization designed to mitigate counterparty risk works well for financial instruments subject to bilateral credit risk, but fails for ones subject to multilateral credit risk.

\section{Appendix}

Proof of Proposition 1. Let $t=T_{0}$. On the first cash flow payment date $T_{1}$, let $V\left(T_{1}\right)$ denote the market value of the instrument excluding the current cash flow $X_{1}$. According to Equation (10), we have

$$
V(t)=E\left[K\left(T_{0}, T_{1}\right)\left(X_{1}+V\left(T_{1}\right)\right) \mid F_{t}\right]
$$

Similarly, we have

$$
V\left(T_{1}\right)=E\left[K\left(T_{1}, T_{2}\right)\left(X_{2}+V\left(T_{2}\right)\right) \mid F_{T_{1}}\right\rfloor
$$


Note that $K\left(T_{0}, T_{1}\right)$ is $F_{T_{1}}$-measurable. According to taking out what is known and tower properties of conditional expectation, we have

$$
\begin{aligned}
V(t)= & E\left[K\left(T_{0}, T_{1}\right)\left(X_{1}+V\left(T_{1}\right)\right) \mid F_{t}\right]=E\left[K\left(T_{0}, T_{1}\right) X_{1} \mid F_{t}\right] \\
& +E\left\{K\left(T_{0}, T_{1}\right)\left[E\left(K\left(T_{1}, T_{2}\right) X_{2} \mid F_{T_{1}}\right)+E\left(K\left(T_{1}, T_{2}\right) V\left(T_{2}\right) \mid F_{T_{1}}\right)\right] \mid F_{t}\right\} \\
= & E\left[K\left(T_{0}, T_{1}\right) X_{1} \mid F_{t}\right]+E\left[\left(\prod_{j=0}^{1} K\left(T_{j}, T_{j+1}\right)\right) X_{2} \mid F_{t}\right]+E\left[\left(\prod_{j=0}^{1} K\left(T_{j}, T_{j+1}\right)\right) V\left(T_{2}\right) \mid F_{t}\right]
\end{aligned}
$$

By recursively deriving from $T_{2}$ forward over $T_{m}$, where $V\left(T_{m}\right)=X_{m}$, we have

$$
V(t)=\sum_{i=1}^{m} E\left\lfloor\left(\prod_{j=0}^{i-1} K\left(T_{j}, T_{j+1}\right)\right) X_{i} \mid F_{t}\right\rfloor
$$

Proof of Proposition 3. Let $t=T_{0}$. On the first payment date $T_{1}$, let $V\left(T_{1}\right)$ denote the market value of the CDS excluding the current cash flow $X_{1}$. There are a total of eight $\left(2^{3}=8\right)$ possible states shown in Table A1. The risky price is the discounted expectation of the payoffs and is given by

$$
\begin{aligned}
V(t)= & E\left\{\mid 1_{\left(V\left(T_{1}\right) X_{1} \geq 0\right.}\left\langle\left(p_{000}\left(T_{0}, T_{1}\right)+p_{100}\left(T_{0}, T_{1}\right) \bar{\varphi}_{B}\left(T_{1}\right)+p_{010}\left(T_{0}, T_{1}\right) \varphi_{B}\left(T_{1}\right)+p_{110}\left(T_{0}, T_{1}\right) \varphi_{A B}\left(T_{1}\right)\right)\left(V\left(T_{1}\right)+X_{1}\right) \mid \mathrm{F}_{\mathrm{t}}\right\rangle\right. \\
& +1_{\left(V\left(T_{1}\right)+X_{1}\right)<0}\left\langle\left(p_{000}\left(T_{0}, T_{1}\right)+p_{100}\left(T_{0}, T_{1}\right) \varphi_{A}\left(T_{1}\right)+p_{010}\left(T_{0}, T_{1}\right) \bar{\varphi}_{A}\left(T_{1}\right)+p_{110}\left(T_{0}, T_{1}\right) \varphi_{A B}\left(T_{1}\right)\right)\left(V\left(T_{1}\right)+X_{1}\right) \mid \mathrm{F}_{\mathrm{t}}\right\rangle \\
& \left.\left.+\left(p_{001}\left(T_{0}, T_{1}\right)+p_{101}\left(T_{0}, T_{1}\right) \bar{\varphi}_{B}\left(T_{1}\right)+p_{011}\left(T_{0}, T_{1}\right) \varphi_{B}\left(T_{1}\right)+p_{111}\left(T_{0}, T_{1}\right) \varphi_{A B}\left(T_{1}\right)\right) R\left(T_{s}, T_{1}\right) \mid \mathrm{F}_{\mathrm{t}}\right] D(t, T)\right\} \\
= & E\left\{\left[O\left(T_{0}, T_{1}\right)\left(V\left(T_{1}\right)+X_{1}\right)+\Omega\left(T_{0}, T_{1}\right) R\left(T_{s}, T_{1}\right)\right] \mid \mathrm{F}_{\mathrm{t}}\right\}
\end{aligned}
$$

where

$$
\begin{aligned}
& O\left(T_{0}, T_{1}\right)=1_{\left(V\left(T_{1}\right)+X_{1}\right) \geq 0} \phi_{B}\left(T_{0}, T_{1}\right)+1_{\left(V\left(T_{1}\right)+X_{1}\right)<0} \phi_{A}\left(T_{0}, T_{1}\right) \\
\phi_{A}\left(T_{0}, T_{1}\right)= & \left\{p_{A}\left(T_{0}, T_{1}\right) p_{B}\left(T_{0}, T_{1}\right) p_{C}\left(T_{0}, T_{1}\right)+q_{A}\left(T_{0}, T_{1}\right) p_{B}\left(T_{0}, T_{1}\right) p_{C}\left(T_{0}, T_{1}\right) \varphi_{A}\left(T_{1}\right)\right. \\
+ & p_{A}\left(T_{0}, T_{1}\right) q_{B}\left(T_{0}, T_{1}\right) p_{C}\left(T_{0}, T_{1}\right) \bar{\varphi}_{A}\left(T_{1}\right)+q_{A}\left(T_{0}, T_{1}\right) q_{B}\left(T_{0}, T_{1}\right) p_{C}\left(T_{0}, T_{1}\right) \varphi_{A B}\left(T_{1}\right) \\
+ & p_{C}\left(T_{0}, T_{1}\right) \sigma_{A B}\left(T_{0}, T_{1}\right)\left(1-\varphi_{A}\left(T_{1}\right)-\bar{\varphi}_{A}\left(T_{1}\right)+\varphi_{A B}\left(T_{1}\right)\right) \\
+ & \sigma_{A C}\left(T_{0}, T_{1}\right)\left[p_{B}\left(T_{0}, T_{1}\right)\left(1-\varphi_{A}\left(T_{1}\right)\right)+q_{B}\left(T_{0}, T_{1}\right)\left(\bar{\varphi}_{A}\left(T_{1}\right)-\varphi_{A B}\left(T_{1}\right)\right)\right] \\
+ & \sigma_{B C}\left(T_{0}, T_{1}\right)\left[p_{A}\left(T_{0}, T_{1}\right)\left(1-\bar{\varphi}_{A}\left(T_{1}\right)\right)+q_{A}\left(T_{0}, T_{1}\right)\left(\varphi_{A}\left(T_{1}\right)-\varphi_{A B}\left(T_{1}\right)\right)\right] \\
+ & \left.\theta_{A B C}\left(T_{0}, T_{1}\right)\left(-1+\bar{\varphi}_{A}\left(T_{1}\right)-\varphi_{A B}\left(T_{1}\right)+\varphi_{A}\left(T_{1}\right)\right)\right\} D\left(T_{0}, T_{1}\right) \\
\phi_{B}\left(T_{0}, T_{1}\right)= & \left\{p_{A}\left(T_{0}, T_{1}\right) p_{B}\left(T_{0}, T_{1}\right) p_{C}\left(T_{0}, T_{1}\right)+q_{A}\left(T_{0}, T_{1}\right) p_{B}\left(T_{0}, T_{1}\right) p_{C}\left(T_{0}, T_{1}\right) \bar{\varphi}_{B}\left(T_{1}\right)\right. \\
+ & p_{A}\left(T_{1}, T_{1}\right) q_{B}\left(T_{0}, T_{1}\right) p_{C}\left(T_{0}, T_{1}\right) \varphi_{B}\left(T_{1}\right)+q_{A}\left(T_{0}, T_{1}\right) q_{B}\left(T_{0}, T_{1}\right) p_{C}\left(T_{0}, T_{1}\right) \varphi_{A B}\left(T_{1}\right) \\
+ & p_{C}\left(T_{0}, T_{1}\right) \sigma_{A B}\left(T_{0}, T_{1}\right)\left(1-\varphi_{B}\left(T_{1}\right)-\bar{\varphi}_{B}\left(T_{1}\right)+\varphi_{A B}\left(T_{1}\right)\right) \\
+ & \sigma_{A C}\left(T_{0}, T_{1}\right)\left[p_{B}\left(T_{0}, T_{1}\right)\left(1-\bar{\varphi}_{B}\left(T_{1}\right)\right)+q_{B}\left(T_{0}, T_{1}\right)\left(\varphi_{B}\left(T_{1}\right)-\varphi_{A B}\left(T_{1}\right)\right)\right] \\
+ & \sigma_{B C}\left(T_{0}, T_{1}\right)\left[p_{A}\left(T_{0}, T_{1}\right)\left(1-\varphi_{B}\left(T_{1}\right)\right)+q_{A}\left(T_{0}, T_{1}\right)\left(\bar{\varphi}_{B}\left(T_{1}\right)-\varphi_{A B}\left(T_{1}\right)\right)\right] \\
+ & \left.\theta_{A B C}\left(T_{0}, T_{1}\right)\left(-1+\bar{\varphi}_{B}\left(T_{1}\right)-\varphi_{A B}\left(T_{1}\right)+\varphi_{B}\left(T_{1}\right)\right)\right\} D\left(T_{0}, T_{1}\right)
\end{aligned}
$$




$$
\begin{aligned}
\Omega\left(T_{0}, T\right)= & \left\{p_{A}\left(T_{0}, T\right) p_{B}\left(T_{0}, T\right) q_{C}\left(T_{0}, T\right)+q_{A}\left(T_{0}, T\right) p_{B}\left(T_{0}, T\right) q_{C}\left(T_{0}, T\right) \bar{\varphi}_{B}\left(T_{1}\right)\right. \\
& +p_{A}\left(T_{0}, T\right) q_{B}\left(T_{0}, T\right) q_{C}\left(T_{0}, T\right) \varphi_{B}\left(T_{1}\right)+q_{A}\left(T_{0}, T\right) q_{B}\left(T_{0}, T\right) q_{C}\left(T_{0}, T\right) \varphi_{A B}\left(T_{1}\right) \\
& +q_{C}\left(T_{0}, T\right) \sigma_{A B}\left(T_{0}, T\right)\left(1-\varphi_{B}\left(T_{1}\right)-\bar{\varphi}_{B}\left(T_{1}\right)+\varphi_{A B}\left(T_{1}\right)\right) \\
& -\sigma_{A C}\left(T_{0}, T\right)\left[p_{B}\left(T_{0}, T\right)\left(1-\bar{\varphi}_{B}\left(T_{1}\right)\right)+q_{B}\left(T_{0}, T\right)\left(\varphi_{B}\left(T_{1}\right)-\varphi_{A B}\left(T_{1}\right)\right)\right] \\
& -\sigma_{B C}\left(T_{0}, T\right)\left[p_{A}\left(T_{0}, T\right)\left(1-\varphi_{B}\left(T_{1}\right)\right)+q_{A}\left(T_{0}, T\right)\left(\bar{\varphi}_{B}\left(T_{1}\right)-\varphi_{A B}\left(T_{1}\right)\right)\right] \\
& \left.+\theta_{A B C}\left(T_{0}, T\right)\left(1-\bar{\varphi}_{B}\left(T_{1}\right)+\varphi_{A B}\left(T_{1}\right)-\varphi_{B}\left(T_{1}\right)\right)\right\} D\left(T_{0}, T\right)
\end{aligned}
$$

Similarly, we have

$$
V\left(T_{1}\right)=E\left\{\left[O\left(T_{1}, T_{2}\right)\left(X_{2}+V\left(T_{2}\right)\right)+\Omega\left(T_{1}, T_{2}\right) R\left(T_{1}, T_{2}\right)\right] \mid \mathrm{F}_{\mathrm{T}_{1}}\right\}
$$

Note that $O\left(T_{0}, T_{1}\right)$ is $F_{T_{1}}$-measurable. According to taking out what is known and tower properties of conditional expectation, we have

$$
\begin{aligned}
V(t)= & E\left\{\left[O\left(T_{0}, T_{1}\right)\left(X_{1}+V\left(T_{1}\right)\right)+\Omega\left(T_{0}, T_{1}\right) R\left(T_{0}, T_{1}\right)\right] \mid \mathrm{F}_{\mathrm{t}}\right\}=E\left[O\left(T_{0}, T_{1}\right) X_{1} \mid \mathrm{F}_{\mathrm{t}}\right] \\
& +E\left[\Omega\left(T_{0}, T_{1}\right) R\left(T_{0}, T_{1}\right) \mid \mathrm{F}_{\mathrm{t}}\right]+E\left\{O\left(T_{0}, T_{1}\right) E\left\langle\left[O\left(T_{1}, T_{2}\right)\left(X_{2}+V\left(T_{2}\right)\right)+\Omega\left(T_{1}, T_{2}\right) R\left(T_{1}, T_{2}\right)\right] \mid \mathrm{F}_{\mathrm{T}_{1}}\right\rangle \mid \mathrm{F}_{\mathrm{t}}\right\} \\
= & \sum_{i=1}^{2} E\left[\left(\prod_{j=0}^{i-1} O\left(T_{j}, T_{j+1}\right)\right) X_{i}\right]+\sum_{i=1}^{2} E\left[\left(\prod_{j=0}^{i-2} O\left(T_{j}, T_{j+1}\right)\right) \Omega\left(T_{i-1}, T_{i}\right) R\left(T_{i-1}, T_{i}\right)\right] \\
& +E\left[\left(\prod_{j=0}^{1} O\left(T_{j}, T_{j+1}\right)\right) V\left(T_{2}\right) \mid \mathrm{F}_{\mathrm{t}}\right]
\end{aligned}
$$

By recursively deriving from $T_{2}$ forward over $T_{m}$, where $V\left(T_{m}\right)=X_{m}$, we have

$$
V(t)=\sum_{i=1}^{m} E\left[\left(\prod_{j=0}^{i-1} O\left(T_{j}, T_{j+1}\right)\right) X_{i} \mid \mathrm{F}_{\mathrm{t}}\right\rfloor+\sum_{i=1}^{m} E\left[\left(\prod_{j=0}^{i-2} O\left(T_{j}, T_{j+1}\right)\right) \Omega\left(T_{i-1}, T_{i}\right) R\left(T_{i-1}, T_{i}\right) \mid \mathrm{F}_{\mathrm{t}}\right\rfloor
$$

\section{References}

Arora, Navneet, Priyank Gandhi, and Francis A. Longstaff (2009), "Counterparty credit risk and the credit default swap market," Working paper, UCLA.

Brigo, D., A. Pallavicini, and R. Torresetti (2011), "Credit Models and the Crisis: default cluster dynamics and the Generalized Poisson Loss model,” Journal of Credit Risk, 6: 39-81.

Collin-Dufresne, P., R. Goldstein, and J. Helwege (2003), "Is credit event risk priced? Modeling contagion via the updating of beliefs," Working paper, Haas School, University of California, Berkeley. 
Das, S., D. Duffie, N. Kapadia, and L. Saita (2007), “Common failings: How corporate defaults are correlated,” Journal of Finance, 62: 93-117.

Das, S., L. Freed, G. Geng, N. Kapadia (2006), “Correlated default risk,” Journal of Fixed Income, 16: 732.

Davis, M., and V. Lo (2001), "Infectious defaults," Quantitative Finance, 1: 382-387.

Deardorff, Alan V. (1982): “The general validity of the Heckscher-Ohlin Theorem,” American Economic Review, 72 (4): 683-694.

Duffie, D., A. Eckner, G. Horel, and L. Saita (2009), "Frailty correlated default," Journal of Finance, 64: 2089-2123.

Duffie, D., and M. Huang (1996), “Swap rates and credit quality,” Journal of Finance, 51: 921-949.

Duffie, D., and K. Singleton (1999), "Modeling term structure of defaultable bonds," Review of Financial Studies, 12: 687-720.

ECB (2009), “Credit default swaps and counterparty risk,” European central bank.

FinPricing, 2019, Market data services, https://finpricing.com/curveVolList.html

Fuijii, M. and A. Takahahsi (2012), "Collateralized CDS and default dependence - Implications for the central clearing," Journal of Credit Risk, 8(3): 97-113. 
Giesecke, K. (2004), “Correlated default with incomplete information,” Journal of Banking and Finance, 28: 1521-1545.

Hull, J. and A. White (2004), "Valuation of a CDO and a nth to default CDS without Monte Carlo simulation," Journal of Derivatives, 12: 8-23.

ISDA (2012), “ISDA margin survey 2012."

Jarrow, R., and S. Turnbull (1995), "Pricing derivatives on financial securities subject to credit risk," Journal of Finance, 50: 53-85.

Jarrow, R., and F. Yu (2001), "Counterparty risk and the pricing of defaultable securities," Journal of Finance, 56: 1765-99.

Johannes, M. and S. Sundaresan (2007), "The impact of collateralization on swap rates," Journal of Finance, 62: 383-410.

J. P. Morgan (1999), “The J. P. Morgan guide to credit derivatives,” Risk Publications.

Koopman, S., A. Lucas, and B. Schwaab (2011), "Modeling frailty-correlated defaults using many macroeconomic covariates," Journal of Econometrics, 162: 312-325.

Lando, D. and M. Nielsen (2010), "Correlation in corporate defaults: contagion or conditional independence?" Journal of Financial Intermediation, 19: 355-372. 
Laurent, J. and J. Gregory (2005), “Basket default swaps, CDOs and factor copulas,” Journal of Risk, 7: $03-122$.

Li, D. (2000), “On default correlation: A copula function approach,” Journal of Fixed Income, 9: 43-54.

Longstaff, F., and E. Schwartz (2001): "Valuing American options by simulation: a simple least-squares approach," The Review of Financial Studies, 14 (1): 113-147.

Madan, D., and H. Unal (1998), "Pricing the risks of default," Review of Derivatives Research, 2: 121160.

Moody’s Investor's Service (2000): “Historical default rates of corporate bond issuers, 1920-99,"

O’Kane, D. and S. Turnbull (2003), “Valuation of credit default swaps,” Fixed Income Quantitative Credit Research, Lehman Brothers, QCR Quarterly, Q1/Q2: 1-19.

Piterbarg, V. (2010), "Funding beyond discounting: collateral agreements and derivatives pricing," Risk Magazine, 2010 (2): 97-102.

Teugels, J. (1990), "Some representations of the multivariate Bernoulli and binomial distributions," Journal of Multivariate Analysis, 32: 256-268.

Xiao, T. (2011), “An efficient lattice algorithm for the LIBOR market model,” Journal of Derivatives, 19 (1): 25-40. 
Zhang, G., and P. Jorion, (2007), "Good and bad credit contagion: Evidence from credit default swaps," Journal of Financial Economics 84: 860-883.

\section{Table 1. Payoffs of a bilateral risky instrument}

This table shows all possible payoffs at time $t+\Delta t$. In the case of $V(t+\Delta t) \geq 0$, there are a total of four cases: i) Both $A$ and $B$ survive with probability $p_{00}$. The instrument value is equal to the market value: $V(t+\Delta t)$. ii) $A$ defaults but $B$ survives with probability $p_{10}$. The instrument value is a fraction of the market value: $\bar{\varphi}_{B}(t+\Delta t) V(t+\Delta t)$ where $\bar{\varphi}_{B}$ represents the non-default recovery rate. $\bar{\varphi}_{B}=0$ represents the one-way settlement rule, while $\bar{\varphi}_{B}=1$ represents the two-way settlement rule. iii) $A$ survives but $B$ defaults with probability $p_{01}$. The instrument value is a fraction of the market value: $\varphi_{B}(t+\Delta t) V(t+\Delta t)$, where $\varphi_{B}$ represents the default recovery rate. 4) Both $A$ and $B$ default with probability $p_{11}$. The instrument value is a fraction of the market value: $\varphi_{A B}(t+\Delta t) V(t+\Delta t)$, where $\varphi_{A B}$ denotes the joint recovery rate when both parties $A$ and $B$ default simultaneously. A similar logic applies to the case of $V(t+\Delta t)<0$

\begin{tabular}{|l|l|l|l|l|}
\hline State & $Y_{A}=0, Y_{B}=0$ & $Y_{A}=1, Y_{B}=0$ & $Y_{A}=0, Y_{B}=1$ & $Y_{A}=1, Y_{B}=1$ \\
\hline Comments & A and B survive & A defaults, B survives & A survives, B defaults & A and B default \\
Probability & $p_{00}$ & $p_{10}$ & $p_{01}$ & $p_{11}$ \\
Payoff if $V(t+\Delta t) \geq 0$ & $V(t+\Delta t)$ & $\bar{\varphi}_{B}(t+\Delta t) V(t+\Delta t)$ & $\varphi_{B}(t+\Delta t) V(t+\Delta t)$ & $\varphi_{A B}(t+\Delta t) V(t+\Delta t)$ \\
Payoff if $V(t+\Delta t)<0$ & $V(t+\Delta t)$ & $\varphi_{A}(t+\Delta t) V(t+\Delta t)$ & $\bar{\varphi}_{A}(t+\Delta t) V(t+\Delta t)$ & $\varphi_{A B}(t+\Delta t) V(t+\Delta t)$ \\
\hline
\end{tabular}




\section{Table 2: Current/spot market data}

This table displays the current (spot) market data used for all calculations in this paper, including the term structure of continuously compounded interest rates, the term structure of A-rated breakeven CDS spreads, and the curve of at-the-money caplet volatilities.

\begin{tabular}{|c|ccccccccccc|}
\hline Term (days) & 31 & 91 & 182 & 365 & 548 & 730 & 1095 & 1825 & 2555 & 3650 & 5475 \\
\hline Interest Rate & 0.0028 & 0.0027 & 0.0029 & 0.0043 & 0.0071 & 0.0102 & 0.016 & 0.0249 & 0.0306 & 0.0355 & 0.0405 \\
Credit Spread & 0.0042 & 0.0042 & 0.0042 & 0.0045 & 0.0049 & 0.0052 & 0.0058 & 0.007 & 0.0079 & 0.0091 & 0.0106 \\
Caplet Volatility & 0.3267 & 0.331 & 0.3376 & 0.3509 & 0.3641 & 0.3773 & 0.308 & 0.2473 & 0.2141 & 0.1678 & 0.1634 \\
\hline
\end{tabular}


Table 3. Impact of the credit quality of the fixed-rate payer on swap rates

This table shows the effect of counterparty credit quality on swap rates. Assume $\rho_{A B}=\varphi_{A B}=0$. The 1 st data column represents the risk-free results. For the remaining columns, we assume that party $B$ is riskfree and party $A$ is risky. 'A $+100 \mathrm{bps'} \mathrm{represents} \mathrm{a} \mathrm{'} 100$ basis points' parallel shift in the A-rated CDS spreads. The results in the row 'Difference from Risk-Free' = risky swap rate - risk free swap rate.

\begin{tabular}{|c|c|ccccc|}
\hline \multirow{2}{*}{ Credit Quality } & $\begin{array}{r}\text { Party } \boldsymbol{A} \\
\text { Party } \boldsymbol{B}\end{array}$ & - & A & A+100bps & A+200bps & A+300bps \\
& Swap Rate & 0.03433 & - & - & - & - \\
\hline \multicolumn{2}{|c|}{ Difference from Risk-Free } & 0 & $0.012 \%$ & $0.026 \%$ & $0.04 \%$ & $0.052 \%$ \\
\hline
\end{tabular}




\section{Table 4: Risk-neutral parameters for CIR model}

This table presents the risk-neutral parameters that are calibrated to the current market shown in Table 2 . 'A+100bps' represents a '100 basis points' parallel shift in the A-rated CDS spreads.

\begin{tabular}{|c|cccc|}
\hline Credit Quality & A & A+100bps & A+200bps & A+300bps \\
\hline Long-Term Mean $a$ & 0.035 & 0.056 & 0.077 & 0.099 \\
Mean Reverting Speed $\boldsymbol{b}$ & 0.14 & 0.18 & 0.25 & 0.36 \\
Volatility $\sigma$ & 0.022 & 0.028 & 0.039 & 0.056 \\
\hline
\end{tabular}




\section{Table 5: Impact of the credit quality of the protection buyer on CDS premia}

This table shows how the CDS premium increases as the credit quality of party $A$ decreases. The 1 st data column represents the counterparty-risk-free results. For the remaining columns, we assume that party $B$ is risk-free and party $A$ is risky. 'A+100bps' represents a '100 basis points' parallel shift in the A-rated CDS spreads. The results in the row 'Difference from Risk-Free' = current CDS premium - counterpartyrisk-free CDS premium.

\begin{tabular}{|c|c|ccccc|}
\hline Credit Quality & $\begin{array}{r}\text { Party } \boldsymbol{A} \\
\text { Party } \boldsymbol{B}\end{array}$ & - & $\mathrm{A}$ & $\mathrm{A}+100 \mathrm{bps}$ & $\mathrm{A}+200 \mathrm{bps}$ & $\mathrm{A}+300 \mathrm{bps}$ \\
& - & - & - & - & - \\
\hline \multicolumn{2}{|c|}{ CDS premium } & 0.027 & 0.02703 & 0.02708 & 0.02713 & 0.02717 \\
Difference from Risk-Free & 0 & $0.003 \%$ & $0.008 \%$ & $0.013 \%$ & $0.017 \%$ \\
\hline
\end{tabular}




\section{Table 6: Impact of the credit quality of the protection seller on CDS premia}

This table shows the decrease in the CDS premium with the credit quality of party $B$. The 1 st data column represents the counterparty-risk-free results. For the remaining columns, we assume that party $A$ is riskfree and party $B$ is risky. 'A +100 bps' represents a ' 100 basis points' parallel shift in the A-rated CDS spreads. The results in the row 'Difference from Risk-Free' = current CDS premium - counterparty-riskfree CDS premium.

\begin{tabular}{|l|l|lllll|}
\hline Credit Quality & Party A & - & - & - & - & - \\
& Party B & - & A & A+100bps & A+200bps & A+300bps \\
\hline CDS premium & 0.027 & 0.02695 & 0.02687 & 0.0268 & 0.02672 \\
Difference from Risk-Free & $0.00 \%$ & $-0.005 \%$ & $-0.013 \%$ & $-0.020 \%$ & $-0.028 \%$ \\
\hline
\end{tabular}




\section{Table A1. Payoffs of a trilateral risky CDS}

This table shows all possible payoffs at time $T_{1}$. In the case of $V\left(T_{1}\right)+X_{1} \geq 0$ where $V\left(T_{1}\right)$ is the market value excluding the current cash flow $X_{1}$, there are a total of eight $\left(2^{3}=8\right)$ possible states: i) $A, B$, and $C$ survive with probability $p_{000}$. The instrument value equals the market value: $V\left(T_{1}\right)+X_{1}$. ii) $A$ defaults, but $B$ and $C$ survive with probability $p_{100}$. The instrument value is a fraction of the market value: $\bar{\varphi}_{B}\left(T_{1}\right)\left(V\left(T_{1}\right)+X_{1}\right)$ where $\bar{\varphi}_{B}, \varphi_{B}$, and $\varphi_{A B}$ are defined in Table 1. iii) $A$ and $C$ survive, but $B$ defaults with probability $p_{010}$. The instrument value is given by $\varphi_{B}\left(T_{1}\right)\left(V\left(T_{1}\right)+X_{1}\right)$. iv) $A$ and $B$ survive, but $C$ defaults with probability $p_{001}$. The instrument value is the default payment: $\left.R\left(T_{0}, T_{1}\right) \cdot \mathrm{v}\right) A$ and $B$ default, but $C$ survives with probability $p_{110}$. The instrument value is given by $\varphi_{A B}\left(T_{1}\right)\left(V\left(T_{1}\right)+X_{1}\right)$. vi) $A$ and $C$ default, but $B$ survives with probability $p_{101}$. The instrument value is a fraction of the default payment: $\bar{\varphi}_{B}(T) R\left(T_{0}, T_{1}\right)$. vii) $B$ and $C$ default, but $A$ survives with probability $p_{011}$, The instrument value is given by $\varphi_{B}(T) R\left(T_{0}, T_{1}\right)$. viii) $A, B$, and $C$ default with probability $p_{111}$. The instrument value is given by $\varphi_{A B}(T) R\left(T_{0}, T_{1}\right)$. A similar logic applies to the case of $V\left(T_{1}\right)+X_{1}<0$.

\begin{tabular}{|l|lll|}
\hline Status & Probability & Payoff if $V\left(T_{1}\right)+X_{1} \geq 0$ & Payoff if $V\left(T_{1}\right)+X_{1}<0$ \\
\hline$Y_{A}=0, Y_{B}=0, Y_{C}=0$ & $p_{000}$ & $V\left(T_{1}\right)+X_{1}$ & $V\left(T_{1}\right)+X_{1}$ \\
$Y_{A}=1, Y_{B}=0, Y_{C}=0$ & $p_{100}$ & $\bar{\varphi}_{B}\left(T_{1}\right)\left(V\left(T_{1}\right)+X_{1}\right)$ & $\varphi_{A}\left(T_{1}\right)\left(V\left(T_{1}\right)+X_{1}\right)$ \\
$Y_{A}=0, Y_{B}=1, Y_{C}=0$ & $p_{010}$ & $\varphi_{B}\left(T_{1}\right)\left(V\left(T_{1}\right)+X_{1}\right)$ & $\bar{\varphi}_{A}\left(T_{1}\right)\left(V\left(T_{1}\right)+X_{1}\right)$ \\
$Y_{A}=0, Y_{B}=0, Y_{C}=1$ & $p_{001}$ & $R\left(T_{0}, T_{1}\right)$ & $R\left(T_{0}, T_{1}\right)$ \\
$Y_{A}=1, Y_{B}=1, Y_{C}=0$ & $p_{110}$ & $\varphi_{A B}\left(T_{1}\right)\left(V\left(T_{1}\right)+X_{1}\right)$ & $\varphi_{A B}\left(T_{1}\right)\left(V\left(T_{1}\right)+X_{1}\right)$ \\
$Y_{A}=1, Y_{B}=0, Y_{C}=1$ & $p_{101}$ & $\bar{\varphi}_{B}(T) R\left(T_{0}, T_{1}\right)$ & $\bar{\varphi}_{B}(T) R\left(T_{0}, T_{1}\right)$ \\
$Y_{A}=0, Y_{B}=1, Y_{C}=1$ & $p_{011}$ & $\varphi_{B}(T) R\left(T_{0}, T_{1}\right)$ & $\varphi_{B}(T) R\left(T_{0}, T_{1}\right)$ \\
$Y_{A}=1, Y_{B}=1, Y_{C}=1$ & $p_{111}$ & $\varphi_{A B}(T) R\left(T_{0}, T_{1}\right)$ & $\varphi_{A B}(T) R\left(T_{0}, T_{1}\right)$ \\
\hline
\end{tabular}




\section{Figure 1. Impact of default correlation on swap rates}

The curve in this diagram represents the sensitivity of swap rates to changes in counterparty default correlation. Party $A$ has an 'A+300bps' credit quality and party $B$ has an 'A' credit quality. 'A+300bps' represents a '300 basis points' parallel shift in the A-rated CDS spreads.

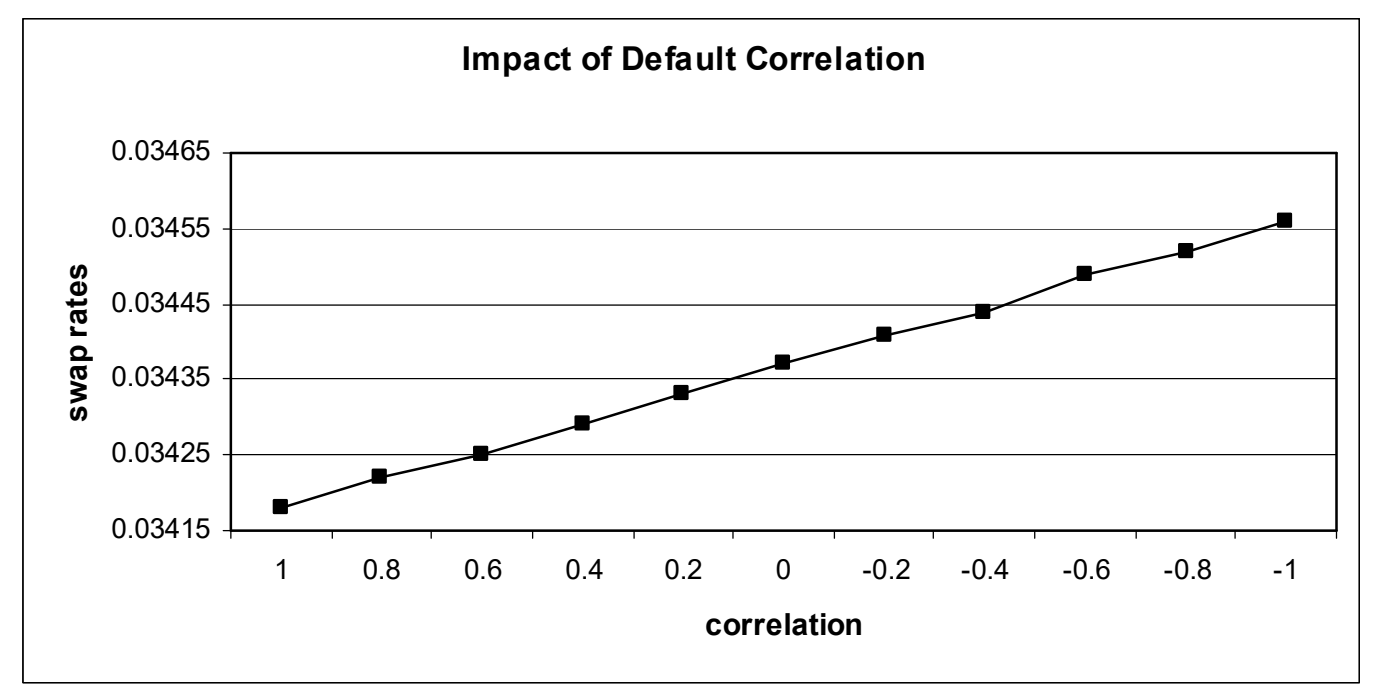




\section{Figure 2: Impact of default correlations and comrelation on CDS premia}

Each curve in this figure illustrates how CDS premium changes as default correlations and comrelation move from -1 to 1 . For instance, the curve 'cor_BC' represents the sensitivity of the CDS premium to changes in the correlation $\rho_{B C}$ when $\rho_{A B}=\rho_{A C}=\zeta_{A B C}=0$.

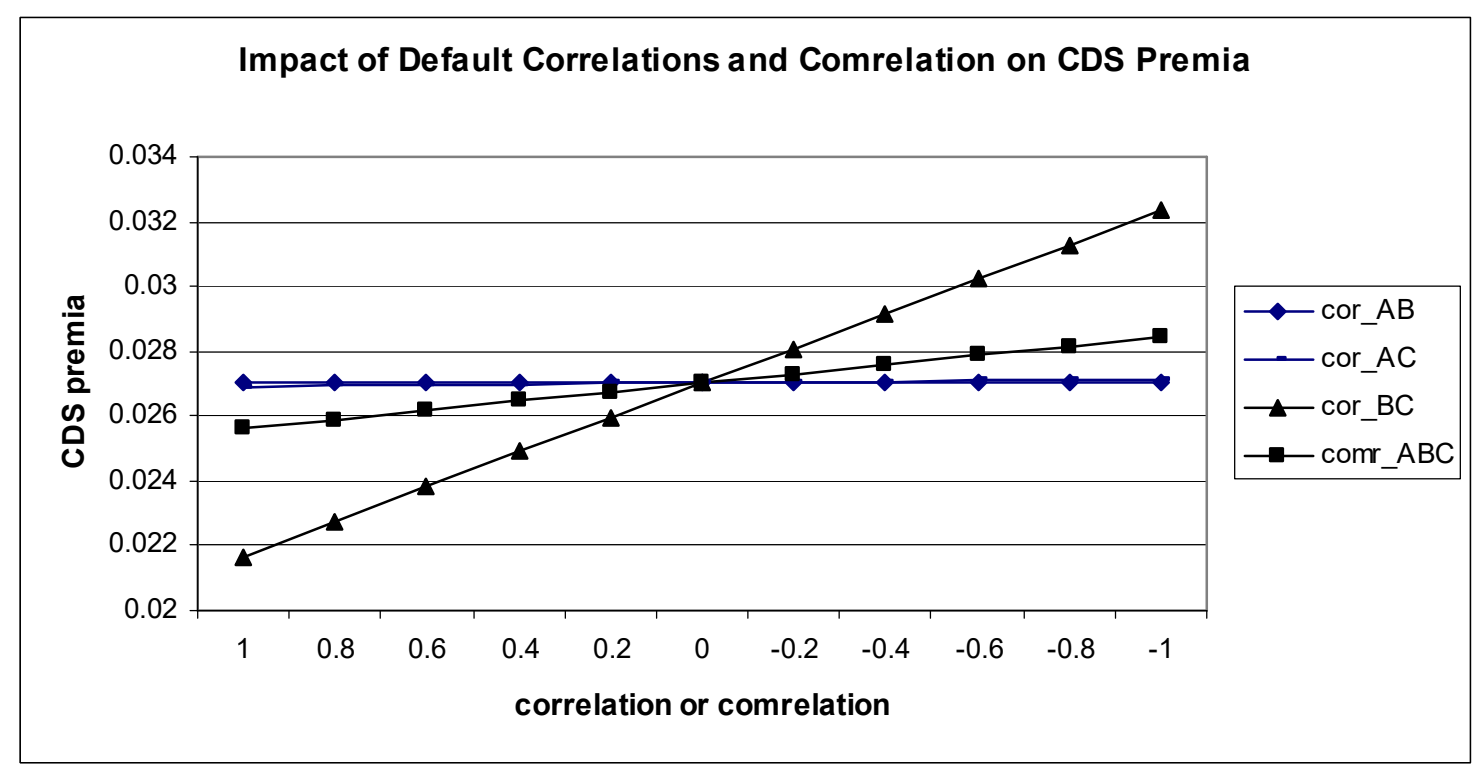

